\title{
Gradhiva
}

GRADHIV

Revue d'anthropologie et d'histoire des arts

$10 \mid 2009$

Présence africaine

\section{Les littératures francophones d'Afrique noire à la conquête de l'édition française (1914-1974)}

The Conquest of French Publishing by Francophone Literature from Sub-

Saharan Africa (1914-1974)

Julien Hage

C OpenEdition

Journals

Édition électronique

URL : https://journals.openedition.org/gradhiva/1523

DOI : $10.4000 /$ gradhiva. 1523

ISSN : 1760-849X

Éditeur

Musée du quai Branly Jacques Chirac

Édition imprimée

Date de publication : 4 novembre 2009

Pagination : 80-105

ISBN : 978-2-35744-012-8

ISSN : 0764-8928

Référence électronique

Julien Hage, « Les littératures francophones d'Afrique noire à la conquête de l'édition française

(1914-1974) », Gradhiva [En ligne], 10 | 2009, mis en ligne le 04 novembre 2012, consulté le 21 septembre 2021. URL : http://journals.openedition.org/gradhiva/1523 ; DOI : https://doi.org/10.4000/ gradhiva. 1523

(c) musée du quai Branly 


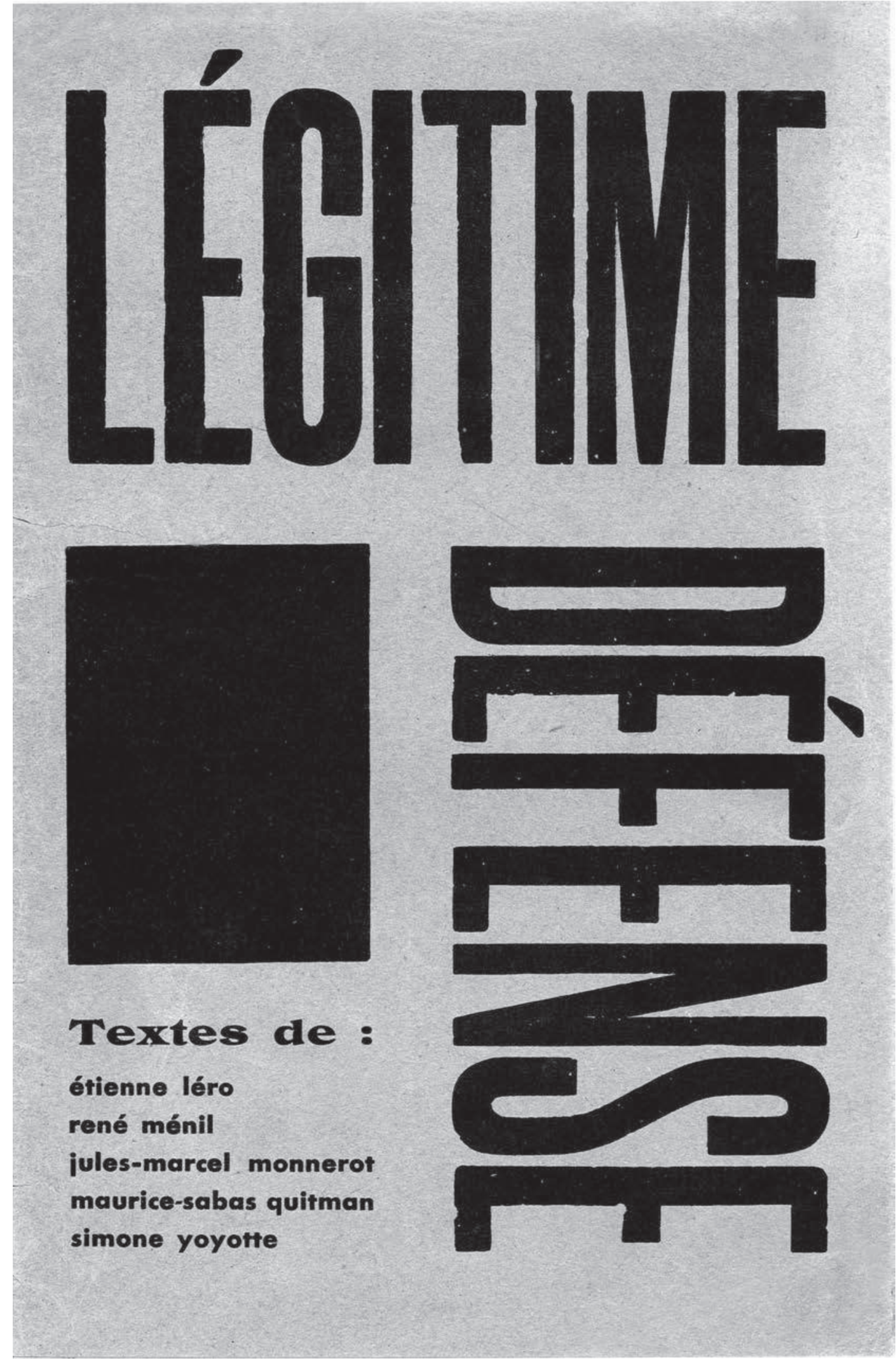

Fig. 1 Légitime Défense, juin 1932 (numéro unique). Revue inspirée par le mouvement surréaliste et fondée par les Antillais Étienne Léro, René Ménil et Jules Marcel Monnerot. Musée du quai Branly. 


\section{Les littératures francophones d'Afrique noire à la conquête de l'édition française (1914-1974)}

Depuis 1808 et l'appel de l'abbé Grégoire à reconnaître l'intelligence africaine à l'égal de l'européenne (Abbé Grégoire 1991 : 185-186), l'intérêt de l'Occident et de ses métropoles colonisatrices pour l'Afrique et pour les productions des peuples dits "primitifs ", déjà présent durant les Lumières, a été croissant, sans qu'il s'agisse pour autant d'un processus linéaire, homogène et global. Au xix et au $\mathrm{xx}^{\mathrm{e}}$ siècle, l'Afrique fut une des terres d'élection privilégiées du roman d'aventures français, de Jules Verne à Henry de Monfreid en passant par Pierre Loti (Astier-Loufti 1971; Fanouh-Siefer 1980). La Première Guerre mondiale a représenté une césure déterminante dans l'évolution du regard français sur l'Afrique et dans l'émergence de nouvelles expressions littéraires consacrées au continent (Riesz et Schulz 1989). Dans les années 1920, à la suite de l'Anthologie nègre de Blaise Cendrars et des écrits d'Apollinaire ou de Picasso, les surréalistes se sont emparés du thème du primitivisme noir et des motifs portés par la littérature coloniale (Blachère 1981 ; id. 2003). Mais, comme le soulignait André Gide en 1947 dans son avant-propos au premier numéro de la revue Présence Africaine, «durant longtemps, les peuples dits civilisés n'ont guère prêté attention au monde noir de l'Afrique que pour l'exploiter. Il s'y mêlait parfois un peu de curiosité de la part de certains, du moins, qui restent soucieux de l'étrange ». L'auteur de Voyage au Congo (1927) espérait venue l'ère de la « compréhension " envers les peuples et les sociétés d'Afrique, et annonçait l'avènement de la littérature en leur sein : «Les moyens plastiques, la musique triomphait; la littérature restait en retard, inexistante ou tout du moins insoupçonnable, insoupçonnée » (Gide 1947 : 3). Paris devait en être la principale tribune éditoriale, du fait de son double statut de métropole politique et de lieu privilégié de la consécration littéraire dans le monde (Mollier 1995; id. 2001), bref, en tant que «capitale culturelle » de l'universel (Casanova 1999). 


\section{LES CONDITIONS NOIRES : UNE GÉNÉALOGIE DES DISCOURS}

La naissance d'une littérature africaine au sens « classique » du terme est généralement datée de l'entre-deux-guerres, avec des livres comme Les Trois Volontés de Malic de Diagne (1920), Batouala de Maran (1921), Force-Bonté de Bakary Diallo (1926) ou encore L'Esclave de Félix Couchouro (1929) (Cornevin 1976; Ricard 1995; Chevrier 1996; Hausser et Mathieu 1998; Kesteloot 2001; Buata 2008), plus tardivement donc qu'en Haïti, par exemple, qui disposait depuis le tournant du xIx $x^{e}$ siècle d'une littérature nationale, demeurée ensuite au premier plan sous l'impulsion d'un Jean Price-Mars ou d'un Jacques Roumain. Une telle littérature s'est progressivement libérée du carcan de la littérature dite "coloniale ", puis du statut de « littérature connexe " que lui attribuait en 1958 encore l'Encyclopédie de la Pléiade dans un de ses volumes consacrés aux littératures françaises, aux côtés des littératures d'Haïti ou des Antilles (Queneau 1958), pour s'imposer comme une littérature à part entière, avec ses propres codes et ses classiques. De nombreux facteurs esthétiques, politiques et commerciaux ont longtemps entravé, encadré et déterminé l'émergence de cette expression littéraire : les difficultés rencontrées par ces auteurs pour s'approprier la langue et les usages de la littérature européenne, le manque de lecteurs et de reconnaissance qui dissuadait les grands éditeurs traditionnels d'investir dans des œuvres au succès commercial pour le moins aléatoire, enfin la censure, plus vive encore dans le cadre colonial, qui pouvait à l'occasion sanctionner des expressions historiques, culturelles, identitaires ou politiques jugées trop radicales ou revendicatives.

Cette littérature a suivi un long trajet, politique en même temps qu'esthétique, d'émancipation et de reconnaissance, qui l'a menée des Trois Volontés de Malic, petit roman d'une vingtaine de pages rédigé par un instituteur sénégalais, Amadou Mapaté Diagne, à la suite d'une commande de la librairie Larousse - un ouvrage publié dans la collection des «Livres roses pour la jeunesse " (Cornevin 1976 : 133) et utilisé pour l'apprentissage de la lecture ${ }^{1}$-, jusqu'à sa reconnaissance au milieu des années 1970, prélude à la consécration du premier prix Nobel de littérature attribué pour son œuvre à un Africain, le Nigérian anglophone Wole Soyinka en 1986, deux ans avant l'égyptien Naguib Mahfouz. Il s'agit ici de s'intéresser aux tribunes de ces nouvelles littératures, au traitement qui leur fut réservé par le monde de l'édition et à leur réception en France, pays qui joua un rôle ambivalent vis-à-vis de ces auteurs, du fait qu'il représentait la puissance coloniale d'un point de vue politique, mais aussi le lieu privilégié de la consécration d'un point de vue esthétique, et qu'il leur offrait un lectorat souvent plus important que le lectorat autochtone, même si Hans-Jürgen Lüsebrink a montré qu'il pouvait exister pour ce type de livres un public littéraire - au sens large - en Afrique occidentale (Lüsebrink 1990). L'accès des différents pays à l'indépendance a émancipé davantage encore les auteurs africains du champ éditorial français, grâce à la création de maisons d'édition africaines, capables de publier et de diffuser leurs écrits sur leur propre sol. Nous retiendrons pour le choix des auteurs et des œuvres les mêmes critères que ceux du Catalogue des ouvrages d'écrivains africains [...] entrés à la Bibliothèque nationale (Lordereau 1991), c'està-dire l'ensemble de l'Afrique à l'exception des cinq États du Nord, ainsi que les expressions outre-mer d'une littérature francophone qui s'est revendiquée ou a été perçue comme "noire» sous l'impulsion notamment du mouvement de la négritude, lançant des ponts vers les Antilles, la Guadeloupe, la Guyane, Haïti, Madagascar, ainsi que vers les États-Unis. Nous ne traiterons ici que des ouvra-

1. Birago Diop, dans ses mémoires, le revendique d'ailleurs comme un de ses inspirateurs (Diop 1978: 31). ges de poésie, de théâtre et des romans, ainsi que des essais et des études historiques, même s'il faut garder présent à l'esprit que la culture et la littérature 
africaines sont faites de tradition et d'oralité tout autant que d'un substantiel héritage manuscrit (Ricard 1995 : 63-93). De ce fait, elles ne se restreignent pas à la seule émergence de leur forme littéraire, au sens classique, en langue française (Gérard 1992), même si l'écho de telles expressions dans l'édition française reste beaucoup plus marginal.

\section{L'entre-deux-guerres : premiers pas}

Quelques livres parus au lendemain de la guerre témoignent de l'émergence d'une littérature de fiction africaine (Fabre 1990), dont Bernard Mouralis a étudié en détail les paliers successifs et les différents facteurs dans son ouvrage Littérature et développement (Mouralis 1984).

Tout d'abord, en 1921, le prix Goncourt revient à Batouala de René Maran (Onana 2007 : 63-82), un administrateur des colonies françaises d'origine guyanaise. Dans sa préface, Maran place son récit de la vie de l'Oubangui-Chari (l'actuelle Centrafrique) dans l'optique d'une critique des excès de la colonisation et des prétentions de la civilisation occidentale. Il se réfère en effet d'une manière relativement inédite à une conscience critique globale émanant des pays colonisés ${ }^{2}$, invoquant les paroles prononcées en 1916 à Tokyo par l'écrivain indien Tagore, prix Nobel de littérature en 1913 : «Civilisation, civilisation, orgueil des Européens, et leur charnier d'innocents, Rabindranath Tagore, le poète hindou, un jour à Tokyo, a dit ce que tu étais " (Maran 1921 : 11). Pour autant, Maran reste dans le cadre d'expression de la littérature française classique et n'envisage pas encore la possibilité d'une littérature noire à part entière, et cela bien qu'il soit lui-même très au fait des situations américaine et haïtienne. Près de vingt ans plus tard, lorsque, une fois reconnu comme un précurseur par Senghor et par une partie de la nouvelle génération d'auteurs de la négritude, il reprendra le texte de Batouala pour une nouvelle édition, il infléchira son écriture pour l'éloigner du français rigoureux de la première mouture (Hausser 1975: 56-57). Pour autant, malgré son succès - la seconde version du livre atteint en 1948 un tirage de deux cent mille exemplaires dans la nouvelle petite collection à bon marché d'Albin Michel (3,75 francs de l'époque, soit 3,80 euros d'aujourd'hui) -, l'ouvrage vaudra à son auteur un scandale retentissant(Rubiales 2005) plus qu'une réelle consécration littéraire; l'on redoutera même que son livre soit utilisé aux fins de la propagande allemande (Porra 1994). À cause de sa préface, Batouala est en effet interdit de diffusion en Afrique, et son auteur se voit contraint de renoncer aussitôt à ses fonctions d'administrateur colonial et de regagner la France en catimini.

Force-Bonté, publié en 1926 dans la maison d'édition progressiste de gauche Rieder et Compagnie, est un exemple de ce qu'Alain Ricard désigne comme une litterrature «mise sous tutelle» (Ricard 1995: 229).
-

2. Tout en demeurant lui-même dans un cadre assimilationniste : on parle aussi de «schoelchérisme». Voir, par exemple, Corzani et al. 1998: 114.

Fig. 2 Batouala, René Maran, Paris, Albin Michel, édition "définitive " de 1938, 1948.

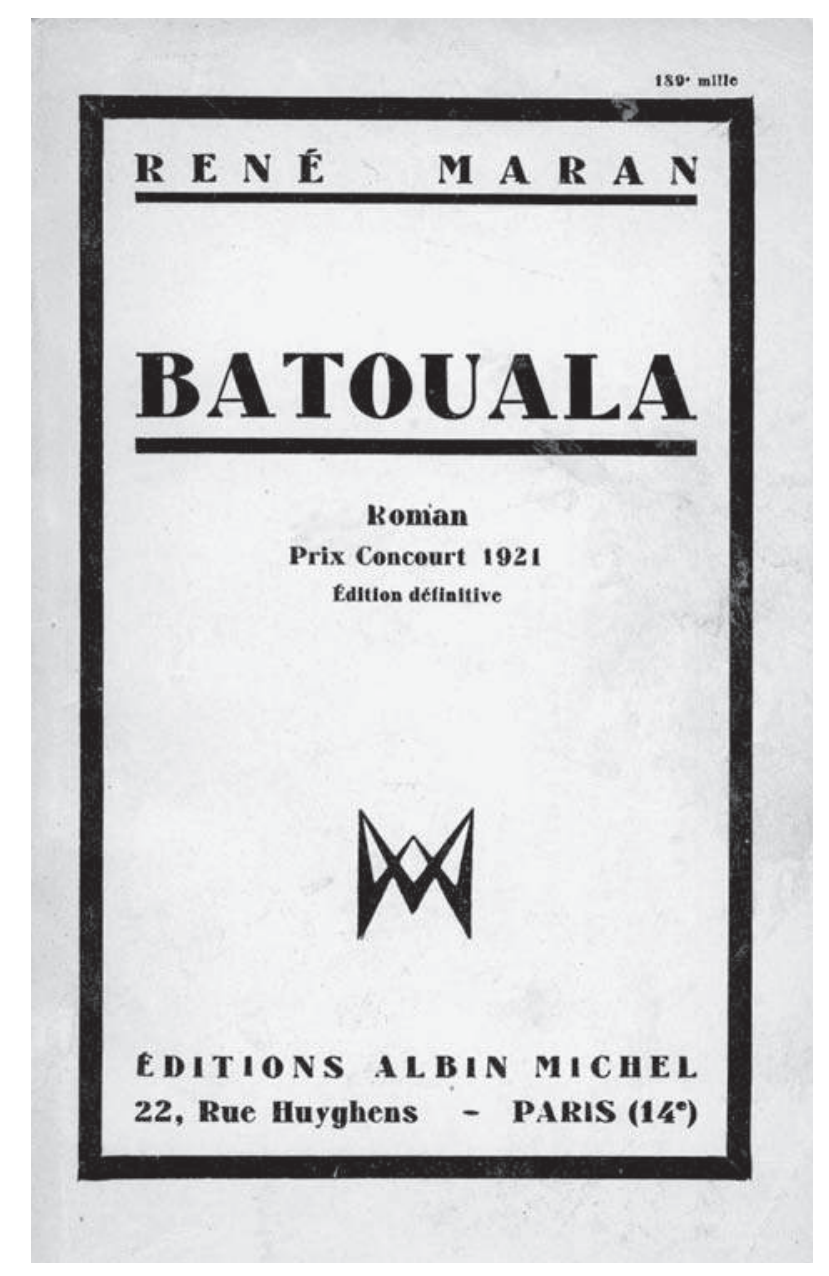




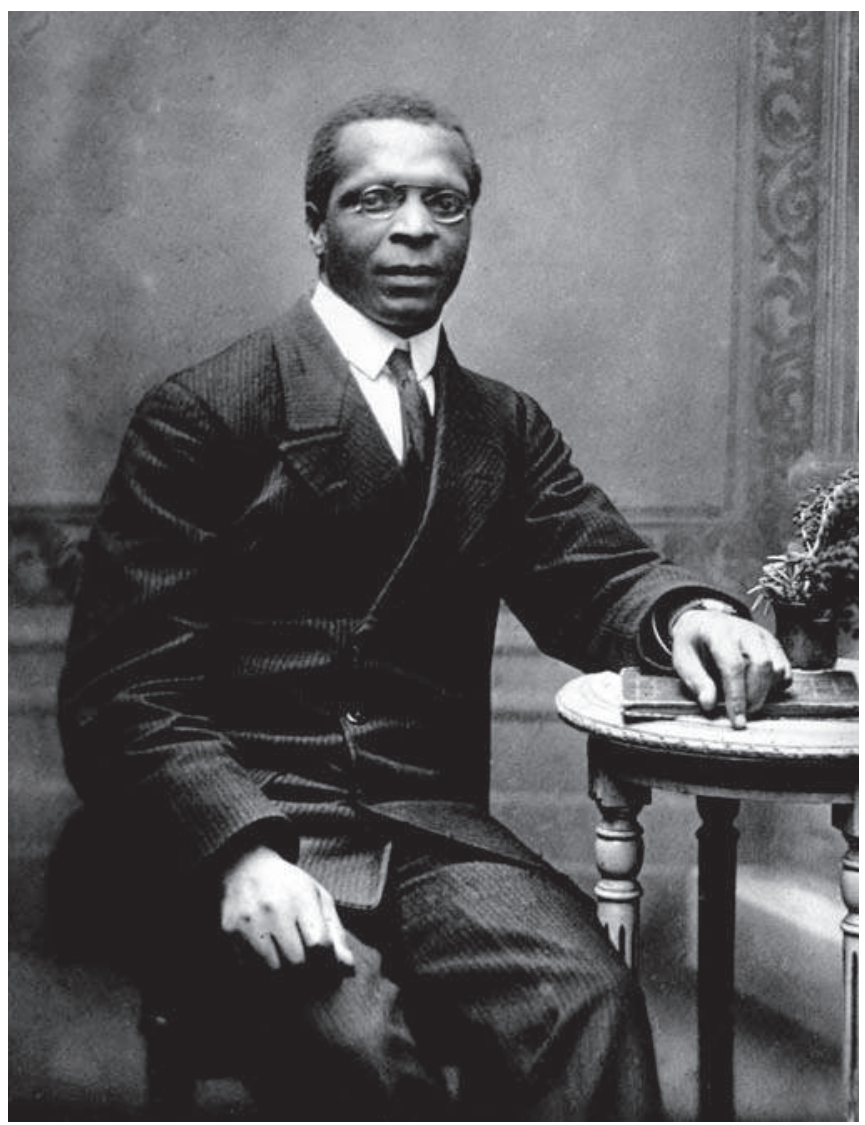

L'auteur, Bakary Diallo, un tirailleur peuhl engagé dans l'armée française, y raconte son parcours, avec une relative complaisance à l'égard de la colonisation, sous la forme d'un appel à la fraternisation. Publié par Jean-Richard Bloch (Albertini 1981) dans une collection qui abrite Gandhi et Israti, l'ouvrage a sans doute été écrit avec l'aide de sa protectrice Lucie Cousturier et de l'éditeur (Geneste 2009). C'est du moins ce qu'affirme le préfacier de la réédition de 1985, Mohamadou Kane : «De toute évidence, de 1911 à 1926, Bakary Diallo n'a pas pu apprendre le français au point d'écrire un roman, alors que de 1911 à 1918, il était occupé à apprendre le métier des armes, à guerroyer, et après, à soigner ses blessures. On sait aussi que l'armée n'est pas la meilleure école pour apprendre la langue et la littérature " (Kane 1985: vIII). En conséquence, «il a dû donner la matière première, le premier jet », avant que ses tuteurs littéraires n'amendent et ne finalisent son texte.

Dans l'entre-deux-guerres, la littérature africaine évolue au sein de la littérature dite "coloniale", qui constitue un genre à part dans la littérature française ${ }^{3}$, souvent avec de grands succès, sanctionnés par des tirages très importants, lorsqu'elle exalte l'aventure, l'exotisme ou

Fig. 3 René Maran (1887-1960). () Studio Lipnitzki / RogerViollet. l'entreprise coloniale, et par des consécrations symboliques et institutionnelles, comme le prix Goncourt, créé en 1903, qui revient à des livres comme Les Civilisés de Claude Farrère (1905), Dingley, l'illustre Africain des frères Jérôme et Jean Tharaud (1906), En France de Marius-Ary Leblond (1910) ou Batouala, déjà cité (1921) (Ruscio 2008). Longtemps, les premiers romanciers africains ne constituent donc qu'une région de cette littérature, ainsi que le montrent les différents sous-titres de leurs livres : Batouala, en 1921, est sous-titré « véritable roman nègre ", Karim, en 1935, «roman sénégalais », ou encore Diab’la, de Jozef Zobel, en 1947, «roman antillais ». En 1931, Roland Lebel insiste dans l'étude qu'il consacre à cette littérature sur l'authentique originalité que revêt à ses yeux l'écriture coloniale : pour lui, «les auteurs coloniaux ne sont plus des métropolitains de passage qui restent attachés à la mère patrie; ils ont opté pour la colonie et c'est non plus d'Europe, mais de la colonie qu'ils regardent couler les événements " (Lebel 1931 : 86, cité in Cornevin $1976: 20$ ).

Pour être reconnus, les écrivains africains d'expression française se trouvent alors soumis, dans un cadre colonial il est vrai un peu différent pour ce qui est de leur statut d'auteurs, à la même contrainte que celle qui pèse sur les écrivains régionalistes étudiés par Anne-Marie Thiesse : la nécessité de «cultiver [leur(s)] différence(s), à défaut de pouvoir s'imposer comme modèles " (Thiesse 1991 : 85). Comme l'affirme par ailleurs le critique Boniface Mongo-Mboussa, «dans les années trente, un écrivain antillais ou africain qui a envie [...] de publier, peut choisir, par exemple, comme stratégie littéraire d'être [...] un écrivain "régional" ou "régionaliste". Il peut donc publier des contes créoles ou des contes traduits d'une langue africaine en français. Ces écrivains [de la "négritude"] n'ont pas 
voulu être des écrivains régionalistes. Ils ont d'abord publié à Paris, on le leur a reproché, je crois que ce n'était pas comprendre leur stratégie " (Mongo-Mboussa, cité in Proteau 2001 : 21). Aussi Paul Hazoumé explique-t-il, dans un "avertissement» en prémabule de son livre Doguicimi, publié chez Larose en 1938 : «Les expressions qui peuvent paraître singulières au lecteur sont la reproduction exacte de l'accent local et la traduction fidèle du langage pittoresque des Dahoméens. Ce parler solennel achèvera, par sa saveur de terroir [...], de communiquer à notre documentation un cachet d'exotisme et d'authenticité, constante préoccupation du vrai régionalisme " (Hazoumé 1938 : 14). Cette intégration au roman régionaliste français constitue donc un premier palier vers la reconnaissance et représente en même temps une première émancipation vis-à-vis de la littérature coloniale, conçue comme littérature d'aventure et d'imagination, ainsi que le souligne Georges Hardy, directeur honoraire de l'École coloniale, alors recteur de l'académie de Lille, à propos du même Doguicimi : "Ou'on se garde d'y voir un roman colonial; il n'invente rien, il se contente de choisir parmi les héros et les événements d'un lieu et d'une époque ceux qui lui paraissent les plus caractéristiques " (Hardy 1938 : 8). Si cette écriture entre dans le cadre d'une reconnaissance régionaliste en vue d'acquérir une légitimité dans le champ littéraire français, elle procède dans le même temps de la volonté d'un retour aux sources et d'une première réappropriation du passé et de l'identité africaine : une «documentation » (pour reprendre le terme d'Hazoumé) destinée à informer et à revendiquer, sous une forme parfois discrète, une histoire et une culture autochtones.

Toute cette génération des premiers auteurs, parmi lesquels Maran, Hazoumé4 ou Damas, s'adonne en effet conjointement à l'écriture de fiction et à l'ethnographie (Riesz 2007b), notamment au musée de l'Homme à Paris. Leurs œuvres représentent incontestablement une réponse à l'ethnologie coloniale de l'entredeux-guerres, avant que cette dernière ne soit pour une grande part assimilée au discours dominant de la colonisation - Mongo Beti n'aura de cesse, dans les années 1960, de dénoncer les travers de l'« ethnologisme». Dans leur écriture, les auteurs peuvent en effet s'opposer aux canons esthétiques et aux présupposés ethnologiques qui sont ceux de cette littérature et que souligne le congolais Félix Couchouro (Ricard 1987) : «L'idée maîtresse, celle qui guide la plume de certains princes de la littérature coloniale, c'est que le Noir évolué, dès qu'il retourne à son milieu, retombe dans l'ornière d'où la civilisation a essayé de le tirer. Et l'on s'acharne à le démontrer. Et les ouvrages qui abondent dans ce sens sont lus avec intérêt. C'est une opinion. On nous permettra de dire qu'elle est contestable. Les héros de ce roman vont le prouver » (Couchouro 1941 : Iv, cité in Ricard 1995 : 231). Avec cette création romanesque, qui se veut en même temps revendication d'une identité et d'un passé niés par la colonisation, on passe progressivement d'une littérature coloniale à une littérature à vocation ethnographique, laquelle sera le creuset de la future littérature africaine en quête de son langage. Tout au long des cinq cents pages de texte de Doguicimi, Hazoumé accumule ainsi les notes de bas de page à vocation documentaire. Dans son livre Négritures, Jean-Claude Blachère analyse en ce sens la démarche d'Ousmane Socé : «La négrification se distingue de l'exotisme lorsqu'il n'est plus question de revêtir, mais de revendiquer. Habiller Hugo d'écorces ouvragées, c'est encore, de quelque manière, lui rendre hommage, se déclarer vassal du français de France; la revendication consiste à déplacer le point de vue. Ce n'est pas pour la gloire de la langue française que veut agir l'écrivain qui, comme Ousmane Socé dans Karim, parsème le texte de mots et de phrases wolofs. C'est d'abord pour la reconnaissance de
-

4. Paul Hazoumé rédige en 1937 une étude intitulée Sur le pacte de sang au Dahomey, qui reçoit le premier prix du gouvernement général de l'Afrique occidentale française (AOF). Une démarche comparable à celle de Jomo Kenyatta dans le cadre des colonies britanniques, avec ses études d'ethnologie sur les Gikuyu rédigées en anglais. 
sa langue maternelle» (Blachère 1993: 122). Les écrivains d'origine autochtone et coloniale ont ainsi dû mener ce que Hans-Jürgen Lüsebrink, appliquant le concept de Jürgen Habermas, appelle la «conquête de l'espace public colonial " (Lüsebrink 1991), avant de conquérir leur droit au chapitre au sein de l'édition française. Janos Riesz insiste sur ce point : « La littérature coloniale française, qui voit son monopole de discours sur l'Afrique remis en cause par ces romans, réagit en publiant une masse impressionnante de romans nègres "véritables", "vrais", "authentiques", en créant des prix de littérature coloniale et prenant ouvertement ses distances face au vieil exotisme d'un Pierre Loti. Ce sont ces romans, écrits par des fonctionnaires ayant l'expérience de l'Afrique, ou certifiés "véritables" par une préface appropriée, qui déterminent l'image française (et par conséquent le champ littéraire) de l'Afrique entre les deux guerres : Koffi, roman vrai d'un noir, Vertige d'Afrique, La Randonnée de Samba Diouf, La Soudanaise et son amant, Fièvres d'Afrique, autant de titres prometteurs et couronnés de succès " (Riesz 2007a : 34).

Dans cette lutte pour la reconnaissance, la médiation des administrateurs coloniaux revêt dans l'entre-deux-guerres une singulière importance. La plupart des livres publiés par des écrivains originaires des colonies disposent en effet d'un paratexte souvent très substantiel (Mateso 1986), afin de présenter le contexte d'une réalité coloniale parfois lointaine et de rassurer le lecteur sur les qualités littéraires de l'ouvrage, voire sur les intentions politiques de l'auteur. Ainsi la préface déjà citée de Georges Hardy à Doguicimi, où il précise : "Vous l'étonneriez fort si vous lui prêtiez la moindre visée autonomiste. Mais à la manière de beaucoup d'entre nous, qui sans cesser un instant d'être d'excellents patriotes, réservent une tendresse particulière à leur région natale, il entend ne pas se détacher inutilement du sol de ses ancêtres, du passé de sa famille, des habitudes de son entourage, de toutes les forces qui ont concouru à former sa personnalité profonde» (Hardy 1938: 10). Assurée en premier lieu par les fonctionnaires en question - même s'ils représentent souvent plus que de simples administrateurs, comme Robert Delavignette, "savant et politique", directeur de l'École nationale de la France d'outre-mer depuis 1937, qui fut aussi un écrivain doué à ses heures (Mouralis et Piriou 2003) -, la médiation l'est aussi par des écrivains français ou par des éditeurs parisiens, qui patronnent en quelque sorte l'auteur. Bientôt, des écrivains et intellectuels français de premier ordre, notamment parmi les surréalistes, vont succéder aux administrateurs coloniaux : la préface de Robert Desnos au recueil Pigments de Léon-Gontran Damas, publié à cinq cents exemplaires en 1937 chez le poète imprimeur Guy Lévis Mano (cat. exp. Roanne 1988), constitue un jalon décisif de cette évolution, bientôt relayé par Retour de Guyane du même auteur, publié l'année suivante chez José Corti, le libraire éditeur proche des surréalistes, qui publie par ailleurs cette année-là $\mathrm{Au}$ château d'Argol, le premier livre de Julien Gracq.

Si ces textes font aujourd'hui figure de précurseurs, et cela même si leur complaisance à l'égard de la colonisation a parfois été mise en cause, comme pour Force-Bonté, la plupart ont été presque complètement oubliés par la suite : Doguicimi n'a été republié qu'en 1978, soit quelque trente années après sa dernière parution, L'Esclave en 1983, et Force-Bonté en 1985. À l'exception de Batouala, constamment réédité, de Karim, régulièrement réédité (il a connu sa cinquième édition en 1958), et des ouvrages de Couchouro - exhumé en Afrique et qui connut, grâce à ses dix-neuf feuilletons échelonnés dans Togo-presse sur huit années (soit près de deux mille pages), une gloire absolument considérable après l'indépendance 


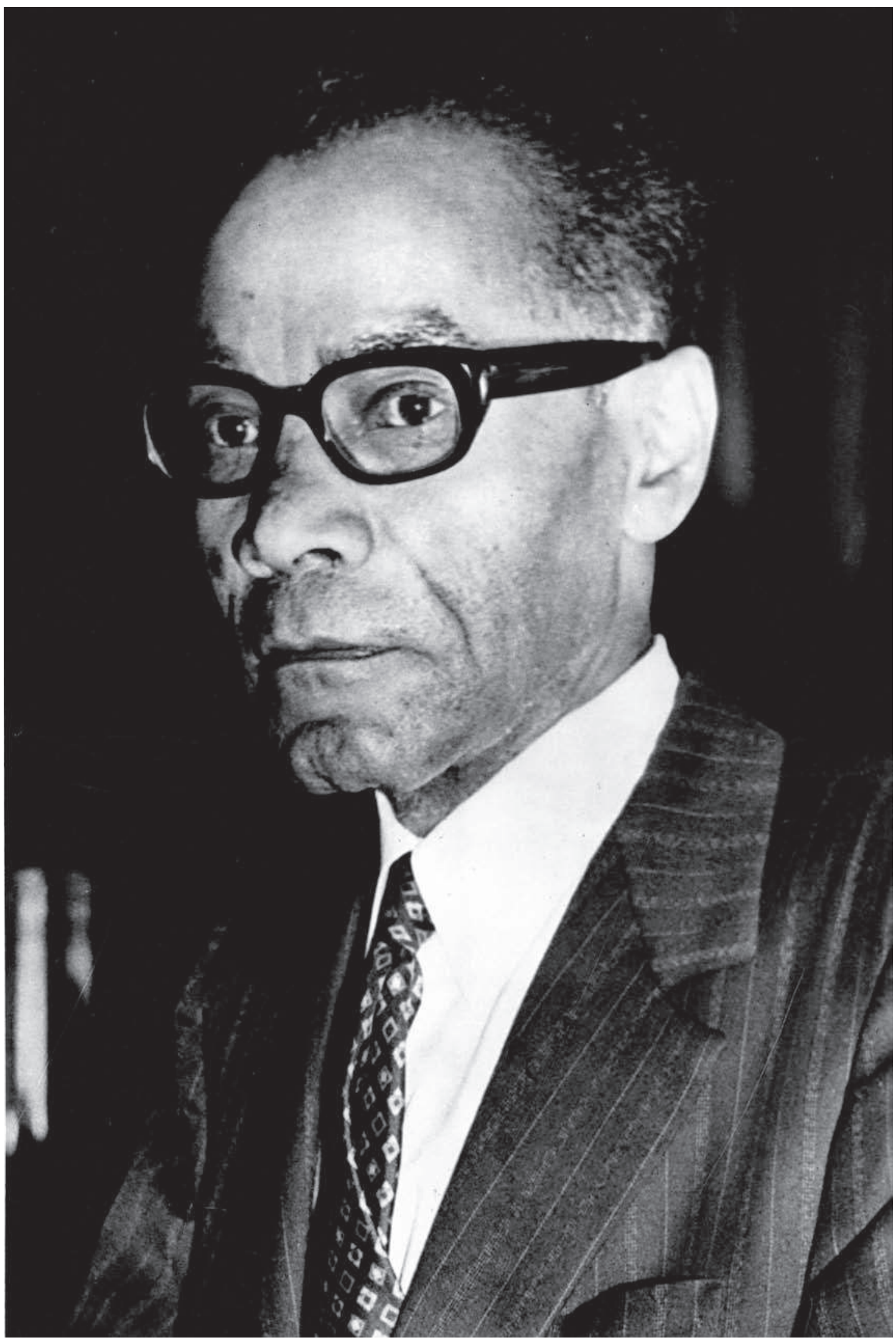

Fig. 4 Portrait de Léon-Gontran Damas (1912-1978) @ Présence Africaine. 
en 1962 (Ricard 1987: 87) -, ces ouvrages, qui demeurent une goutte d'eau dans l'océan de la littérature coloniale, ont été impuissants à imposer leurs auteurs en tant que romanciers à part entière et à les sortir de leur marginalité au sein du champ éditorial français. En revanche, ils ont posé les jalons de plusieurs genres romanesques - le récit initiatique (Force-Bonté), le roman historique et documentaire (Doguicimi), le roman de mœurs (Karim), le roman populaire (L'Esclave, publié aux éditions de La Dépêche africaine) - qui allaient trouver plus tard leurs lettres de noblesse, même si c'est d'abord la poésie qui s'imposa, grâce au mouvement de la négritude porté par quelques revues d'avant-garde.

Au début des années 1930, les intellectuels noirs, pour beaucoup encore étudiants (Dewitte 1985; id. 1989; Steins 1986), sont réunis à Paris dans le quartier Latin, lieu à la fois de formation et d'accueil des exilés. Quelques-uns d'entre eux parviennent à se faire publier dans les plus grandes revues, ainsi Léon-Gontran Damas, qui fait paraître plusieurs de ses poèmes dans la revue Esprit dès 1934, puis dans les Cahiers du Sud en 1936, et surtout l'article "Nègres, misère noire » en 1939, toujours dans Esprit (Damas 1939), ce qui ne l'empêche pas d'être conscient des limites de ces opportunités éditoriales: "Aucune grande revue littéraire paraissant à Paris ne s'est jamais proposée de faire le lien entre les provinces françaises et les territoires d'outre-mer [...] En parcourant les revues éditées à la Colonie, telle que la luxueuse et généreuse Revue de Madagascar [...] on n'est pas surpris de voir le peu d'intérêt accordé aux différentes cultures franco-indigènes " (Damas 1947 : 8). Mais la majorité de ces auteurs font leurs premiers pas dans de nombreuses petites revues d'avant-garde (Van Hove 1987; Antoine 1992 : 153198) qui s'offrent comme autant de lieux de rencontre et de débats esthétiques et politiques. La Dépêche africaine, fondée à Paris en 1928 et dirigée par le guadeloupéen Maurice Salineau, d'inspiration profrançaise et anticommuniste, prône l'assimilation et écarte tout radicalisme ethnique. La Revue du monde noir, publication bilingue français-anglais fondée par le docteur haïtien Sajous et la martiniquaise Paulette Nardal, laquelle tient un salon littéraire, parait du 20 novembre 1931 au 20 avril 1932. Lieu de rencontre entre personnalités du monde noir, comme René Maran ou le Dr Jean Price-Mars, alors sénateur d'Haïti, elle adopte un ton relativement modéré et se voit d'ailleurs subventionnée par le ministère des Colonies. En 1932, l'unique numéro de la revue Légitime défense, rédigé par des dissidents de La Revue du monde noir - qu'ils jugent trop timorée -, comme René Ménil, Jean-Marcel Monnerot ou Étienne Lero, est en revanche une révélation radicale. Prenant la forme d'un manifeste dans une veine surréaliste, la revue tire à boulets rouges sur l'écriture jugée conformiste des écrivains antillais. À l'origine Journal de l'association des étudiants martiniquais, petit périodique corporatiste à l'audience relativement confidentielle, L'Étudiant noir réunit de son côté en 1935, en l'espace de quelques rares numéros, les futurs écrivains de la négritude autour d'Aimé Césaire et de Léon-Gontran Damas. On y trouve ainsi Léopold Sédar Senghor, Léonard Sainville ou encore Ousmane Socé. La revue milite pour une rupture avec l'esthétique classique et pour l'indépendance vis-àvis de la III Internationale, et l'on considère souvent que c'est là, avec l'article de Césaire intitulé « Nègreries », qu'a été forgé le concept de la négritude.

Ces revues sont une tribune littéraire autant qu'un atelier d'écriture pour les jeunes écrivains noirs en quête de droit de cité dans l'édition, tels Léopold Sédar Senghor, qui, en 1939, publie dans la revue Charpentes "Neige sur Paris", un poème repris après guerre dans son recueil Chants d'ombre, ou encore Aimé Césaire pour les premières esquisses du Cahier d'un retour au pays natal. Publiée 
en 1947 chez Bordas sous la forme d'un livre (puis reprise dans une version augmentée et définitive par Présence Africaine en 1956), l'œuvre a connu plusieurs versions préparatoires : d'abord en août 1939, dans le numéro 20 de la revue Volontés, dirigée par Georges Pelorson5, puis en avril 1941, dans le premier numéro de la revue Tropiques (1994:10-23), fondée en Martinique pendant la guerre par Aimé Césaire et son épouse Suzanne, revue dans laquelle André Breton découvre le texte sous cette forme lors de son passage à Fort-de-France. Son enthousiasme immédiat pour un texte qu'il considère comme relevant du surréalisme l'amène à préfacer l'édition de 1947, qui paraît simultanément à Paris et à New York. Cet essor éditorial est à la fois celui de la forme poétique et de la notion de négritude, "mot de passe qui fonctionne plus qu'il ne signifie" (Hausser 1988 : 27). Il trouve là ses premières réalisations concrètes, avant d'être freiné par la guerre et le régime de Vichy, pendant lesquels la censure s'abat sur les ouvrages et les revues. Pigments est interdit et saisi en 1939 pour atteinte à la sûreté de l'État, tandis que Retour en Guyane du même auteur est acheté par l'administration coloniale guyanaise pour le pilonner. Diab'la, écrit en 1940, doit attendre la Libération pour paraître, d'abord à Fort-de-France, puis à Paris, aux Nouvelles Éditions latines, tout comme Gouverneurs de la rosée de l'haïtien Jacques Roumain, qui connaît un succès mondial à la Libération chez les Éditeurs français réunis, proches du Parti communiste. En mai 1943, la revue Tropiques, soumise dès 1941 à une censure préalable qui contraint ses rédacteurs à la modération, est quant à elle interdite d'impression après cinq numéros, au motif qu'elle est "révolutionnaire, raciale et sectaire ${ }^{6}$ ", et ce, jusqu'à ce que la Martinique rejoigne le camp gaulliste. Prisonnier après les combats de juin 1940, dans lesquels il s'est engagé sous l'uniforme français, Senghor sort de son côté de captivité en février 1942, captivité durant laquelle il a écrit une grande partie des poèmes qui seront publiés après guerre dans son recueil Hosties noires, comme de nombreux auteurs de cette génération qui parviennent alors à maturité. Un petit groupe d'intellectuels africains se rassemble alors pour réfléchir à l'avenir de l'Afrique à l'issue du conflit. Si la guerre a retardé l'éclosion de leurs œuvres, la Libération rattrapera vite ce retard.

\section{L'après-guerre : l'essor porté par le mouvement de la négritude}

Après la guerre, les écrivains et intellectuels noirs reprennent leur envol (Dewitte 1994; id. 1998), forts qu'ils sont des nouvelles perspectives issues du congrès de Brazzaville de 1944, dans le cadre de l'Union française, et de la légitimité de l'engagement et du sacrifice des peuples colonisés pour la libération de la France. Ils en sont d'ailleurs souvent à la Libération les porte-parole et les représentants politiques (Benot 1989), comme Senghor, Césaire, Hazoumé ou plus ponctuellement Maran, en 1948-1950. À ce titre, ils sont porteurs d'une double revendication : ils veulent d'une part être reconnus pour eux-mêmes en tant qu'auteurs, et d'autre part, sur un plan plus global et politique, voir le plus grand nombre accéder à la citoyenneté, ce qui se traduira par les lois du printemps 1946 - la loi dite «Houphouët-Boigny" sur l'abolition du travail forcé, puis la loi «Lamine Gueye » supprimant toute distinction entre «sujets » et «citoyens». Portés par l'élan progressiste de l'après-guerre, ces auteurs parvenus à maturité tirent parti de l'opportunité offerte par le centenaire de l'abolition de l'esclavage en 1948 et trouvent de nombreuses occasions de tribunes dans les revues. Esprit leur ouvre
-

5. Volontés 20, août 1939 : 23-42. Sur Volontés, voir Sapiro 1999: 458-459.

6. « Lettre du Lieutenant de vaisseau Bayle au directeur de la revue Tropiques », in Tropiques 1994 : xXXVII-XXXVIII. 


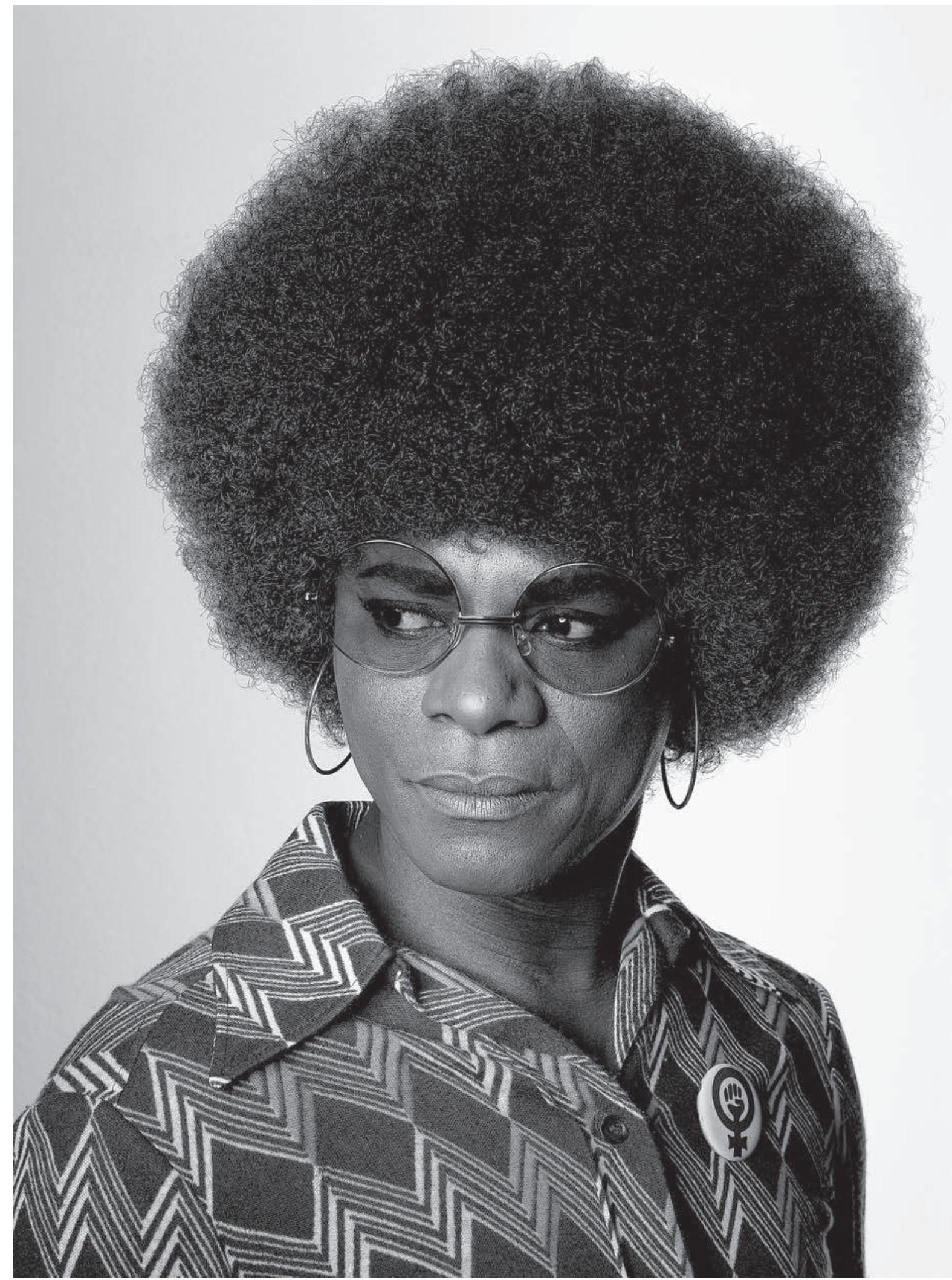

Fig. 5 Samuel Fosso, Autoportrait, «African Spirits», L_002993 @ 2009 Samuel Fosso, avec la permission de jean marc patras / galerie / paris 
fréquemment ses colonnes, tout comme les Cahiers du Sud. Les Temps modernes, la revue créée par Jean-Paul Sartre en octobre 1945, leur donnent aussi la parole, de même que Les Lettres françaises, dirigées par Aragon, ou Europe, autre revue proche des communistes, qui consacre un numéro spécial à l'Afrique en 1949. À titre d'exemple, Senghor à lui seul publie dès 1945 dans Esprit, Les Lettres françaises et les Cahiers du Sud.

Cette entrée dans le champ éditorial français et la revendication d'une reconnaissance à la fois politique et esthétique dont elle s'accompagne se font sous la forme d'anthologies, ce qui est une manière de postuler une solidarité et une unité entre les auteurs, "comme à un rendez-vous idéal et fraternel " (Damas 1947 : 8), afin de revendiquer pour tous voix au chapitre, et de dessiner les contours d'une théorie critique globale. De la première anthologie de Damas à la seconde, parue en 1966 dans le numéro 56 de Présence Africaine, qui révèlent deux générations différentes d'auteurs africains, en passant par celle publiée par la revue Europe en 1949 ou encore par celle de Léonard Sainville, publiée chez Présence Africaine en 1963 et dont le second tome paraît en 1968, les très nombreux recueils sont autant d'occasions de rivaliser. Si Damas ouvre la voie, en présentant avec Latitudes françaises un recueil des textes qu'il a pu regrouper pendant la guerre, c'est l'année suivante, aux Presses universitaires de France (PUF), avec son Anthologie de la nouvelle poésie nègre et malgache de langue française, que Senghor remporte le plus grand succès, dans la collection «Écrits français d'outre mer", alors animée par Charles-André Julien, un conseiller de l'Union française. Là où le recueil de Damas regroupait des auteurs de toutes les colonies françaises, cette anthologie se caractérise surtout par la prédominance des Antillais (dix poètes sur seize), tandis que l'Afrique ne compte que trois représentants: Senghor lui-même, Birago Diop et David Diop, âgé de vingt et un ans seulement, et dont l'œuvre était jusque-là restée inédite. Le livre trouve un grand écho en particulier grâce à la préface de Sartre, "Orphée noir ", qui célèbre l'avènement de l'expression poétique noire. Elle symbolise, de même que la préface d'André Breton au Cahier de Césaire un an auparavant, l'engagement de nombreux intellectuels pour la cause des colonisés et la reconnaissance des voix du tiers-monde, des intellectuels qui prennent le relais des administrateurs coloniaux de l'entre-deux-guerres.

Les nouveaux éditeurs apparus au lendemain de la Seconde Guerre mondiale vont être les principaux protagonistes de l'édition d'auteurs d'Afrique noire. C'est le cas des éditions du Seuil, une maison proche des chrétiens de gauche, créée en 1937 et qui connaît un essor considérable après la guerre, des éditions René Julliard ou encore des éditions Robert Laffont. En 1949, les éditions Présence Africaine, lancées à la suite de la revue avec le livre La Philosophie bantoue du révérend père Placide Tempels, donnent un droit de cité dans le champ éditorial français aux voix et à la littérature africaines, d'abord dans le registre poétique, puis dans le genre romanesque. Camara Laye ou Cheikh Hamidou Kane reconnaîtront plus tard ne pas avoir eu de mal à trouver un éditeur (Blachère 1993 : 51). Dès 1945, Senghor publie Chants d'ombre dans la collection «Pierres vives ». Cette collection, lancée en 1945 sous la direction de Claude-Edmonde Magny, proche d'Esprit, était le lieu d'expérimentation des éditions du Seuil (Serry 2008 : 32-33) : le recueil de Senghor y côtoie ainsi L'Histoire du surréalisme de Maurice Nadeau (1945) ou encore Le Degré zéro de l'écriture de Roland Barthes (1953). En 1947, Léon-Gontran Damas y publie le premier et unique ${ }^{7}$ volume de son anthologie Latitudes françaises. I, Poètes d'expression française: 1900-
-

7. II devait être suivi dans la même collection de deux autres volumes qui ne virent jamais le jour, Romanciers et conteurs d'expression française, et Essayistes d'expression française. 
1945, avant que n'y paraisse Hosties noires, le nouveau recueil de Senghor. Pour autant, malgré l'amitié qui lie Paul Flamand, l'un des fondateurs du Seuil, à ce dernier, une amitié encore renforcée par leurs convictions catholiques communes, il n'y aura pas de collection spécifique consacrée à ces écrivains - alors qu'au même moment Emmanuel Roblès est chargé, avec la collection "Méditerranée ", de s'ouvrir à la littérature du Maghreb, soulignant l'investissement considérable du Seuil dans le domaine des littératures francophones (Éditions du Seuil 2006). En 1958, toujours au Seuil, Édouard Glissant reçoit le prix Renaudot pour La Lézarde. Les éditions Julliard jouent également un grand rôle, d'abord dans l'essor du roman africain, avec le livre de Cheikh Hamidou Kane L'Aventure ambiguë (1961), puis en 1963 avec la collection «Classiques africains", dont chaque volume présente dans une édition bilingue un texte en langue africaine issue de la tradition orale. Maison traditionnelle - elles existent depuis la fin du xix ${ }^{e}$ siècle -, les éditions Fasquelle sont elles aussi à la pointe en ce domaine, avec leur collection "Écrits français d'outre-mer ", dans laquelle Léon-Gontran Damas joue un grand rôle. Elles publient Les Contes d'Amadou Koumba, recueil de contes de Birago Diop écrit en 1942, alors seulement connu par sa présence dans l'Anthologie de la poésie nègre et malgache de langue française. Gallimard s'engage également avec la publication d'Armes miraculeuses de Césaire, bientôt suivie de celle de Compère général soleil de l'haïtien Jacques-Stephen Alexis, puis de Black Label de Damas. Dans le domaine de la poésie, exceptionnellement riche en Afrique, et que Sartre met particulièrement en avant dans "Orphée noir ", deux protagonistes jouent un rôle majeur. Tout d'abord Pierre Seghers, «l'éditeur des poètes ", qui publie dès 1950 Afrique debout!, le premier recueil de poèmes de l'ivoirien Bernard Binlin Dadié, et Poèmes africains de Keita Fodeba, suivis deux ans plus tard de Graffiti de Léon-Gontran Damas. Il accueille par ailleurs les contes Le Maître d'école et Minuit de Keita Fodeba en 1952, puis l'unique œuvre romanesque de Dadié, Climbié, en 1956. L'autre grand éditeur des poètes africains est Pierre-Jean Oswald, très engagé lors de la guerre d'Algérie, ce qui lui vaut de s'exiler en Tunisie. En 1962, il publie Épitomé de Tchicaya U Tam'Si, préfacé par Senghor, à la Société nationale d'édition et de diffusion à Tunis, puis, dans la collection "J'exige la parole", Chant funèbre pour un héros d'Afrique de Pierre Makombé Bamboté, en l'honneur de Patrice Lumumba. Il poursuit dans cette veine avec sa collection «Prose/Poésie africaine», lancée à la fin des années 1960, qui accueille un nombre considérable de poètes africains.

L'essor de l'ethnologie, puis de l'anthropologie, entraîne une évolution du regard porté sur les œuvres des auteurs africains ainsi que des interprétations plus scientifiques et plus mesurées de leur histoire et de leur culture, avec l'émergence de la notion de "tiers-monde" sous l'impulsion d'Alfred Sauvy et de Georges Balandier. La nouvelle préface jointe à la troisième édition de Karim de Ousmane Socé, parue en 1948 aux Nouvelles Éditions latines, dans la collection «Bibliothèque de l'Union française " (comme Diab'la de Zobel), symbolise bien l'apparition d'un nouveau cadre politique et herméneutique. Robert Delavignette invoque d'abord le naturaliste Théodore Monod, qui défend le droit à l'histoire et à la culture des civilisations noires : «Le Noir n'est pas un homme sans passé, il n'est pas tombé d'un arbre avant-hier. L'Afrique est littéralement pourrie de vestiges préhistoriques et certains se demandent même depuis peu si elle n'aurait pas, contrairement à l'opinion courante, vu naître l'homme proprement dit» (Delavignette 1948 : 8-9). Pour autant, le préfacier inscrit encore l'œuvre dans le cadre d'une unité politique avec la France, appelant à « dépasser 


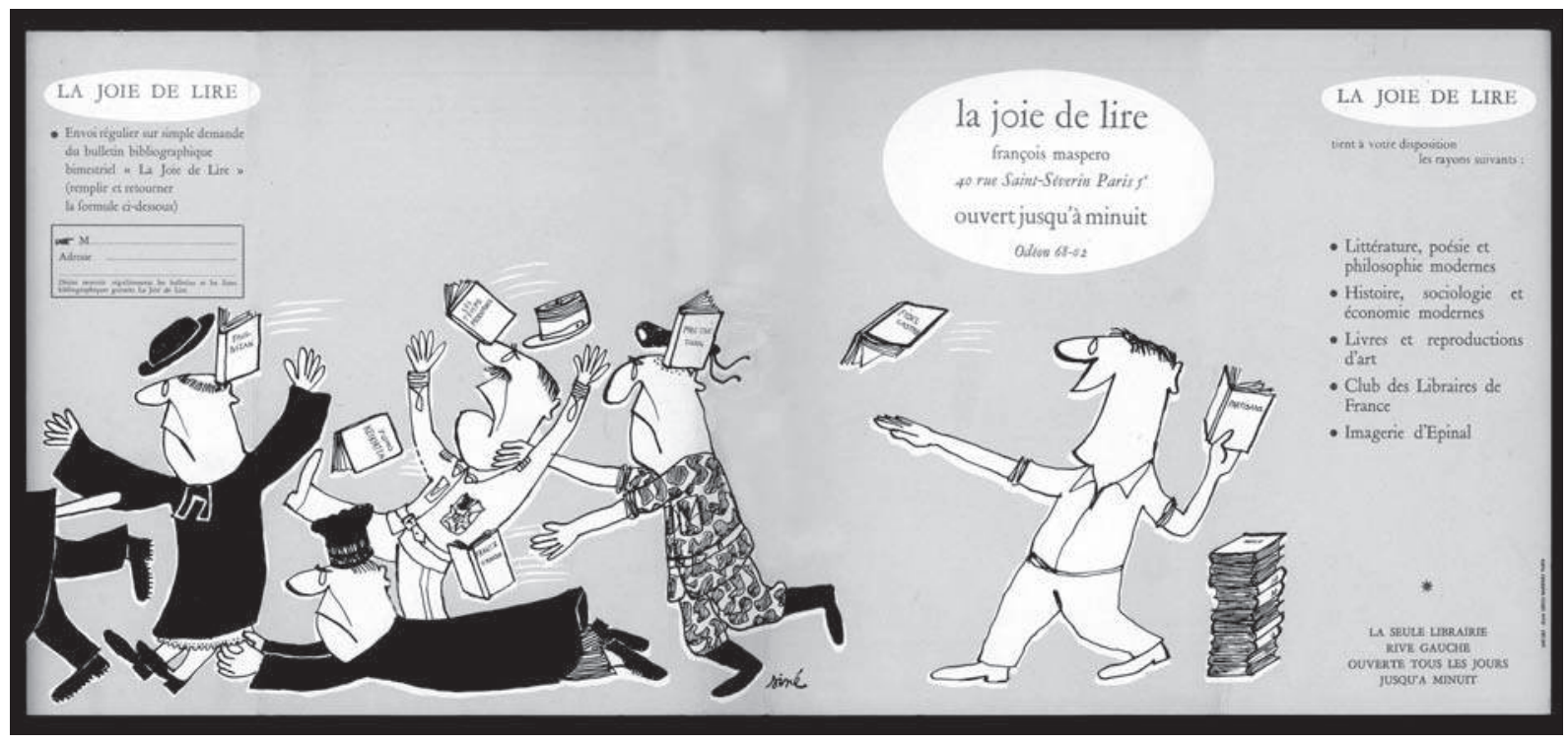

les vieilles notions de colonisation comme le stade du nationalisme africain " (ibid. : 15), et insiste sur le fait que la situation française est vraisemblablement meilleure que la situation américaine, à l'aune de Karim, qui laisse d'après lui plus d'espoir dans cette perspective que le Black Boy de Richard Wright.

Le soutien et l'intérêt croissant des intellectuels français se retrouvent dans la composition du comité de patronage qui préside en 1947 au lancement du premier numéro de la revue Présence Africaine : autour d'Alioune Diop, on y relève les noms de Georges Balandier, Albert Camus, André Gide, Michel Leiris, Théodore Monod, alors directeur de l'Institut français de l'outre-mer, ceux aussi du dominicain et ancien résistant Jean-Pierre Maydieu, d'Emmanuel Mounier - qui avait publié en 1947, après un voyage sur place, L'Éveil de l'Afrique noire -, de l'ethnologue Paul Rivet, directeur du musée de l'Homme, aux côtés de Senghor, Césaire ou Hazoumé, et de l'américain Richard Wright, ainsi que l'ensemble de la direction de la Revue internationale de Pierre Naville. Dans les premiers numéros d'une revue qui se veut à la fois politique et culturelle (Howlett 1976), ce sont les intellectuels français qui nourrissent la plupart des polémiques politiques à l'égard de la colonisation, tandis qu'Alioune Diop appelle à la «collaboration intellectuelle" entre l'Afrique et l'Europe, et que les collaborateurs noirs de la revue y publient surtout leurs premières œuvres et interviennent dans des débats culturels et esthétiques. Si la déclaration d'intention du fondateur de Présence Africaine est très en retrait vis-à-vis des déclarations de Légitime défense en 1932 ou des stances du Cahier d'un retour au pays natal en 1939 - Césaire, du reste, prend vite ses distances -, elle peut s'expliquer par la nécessaire prudence d'une revue qui se revendique explicitement comme «française » et qui est à ce titre soumise à la surveillance des autorités. En revanche, le projet d'une maison d'édition carrefour, «qui ne se place sous l'obédience d'aucune idéologie philosophique ou politique» et qui "veut s'ouvrir à la collaboration de tous les hommes de bonne volonté (blancs, jaunes ou noirs), susceptibles de nous aider à définir l'identité africaine et de hâter son insertion dans le monde moderne ${ }^{8}$ ", est résolument moderne, même s'il trouve bientôt ses limites. La contribution de Présence
Fig. 6 Couvre-livre de Siné conçu pour la librairie "La joie de lire" de François Maspero, durant la guerre d'Algérie. Avec la permission de Siné.
- $\circ$

8. Présence Africaine 1, 1947 : ?. 


\section{LES CONDITIONS NOIRES : UNE GÉNÉALOGIE DES DISCOURS}

Africaine à la reconnaissance de la littérature africaine est en tout cas considérable, à la mesure de la formidable opportunité éditoriale qu'a fait naître la revue : on ne compte plus le nombre d'auteurs qui y ont publié leurs premières œuvres. D'autres revues apparues au même moment, comme La Voix du COGES, ensuite devenue Réalités africaines (1948-1949), revue gabonaise paraissant à Paris, ou encore Résonances, qui donne une voix à l'Afrique équatoriale française, connaissent moins de succès (Bancel et Devisse 1993; Städler 2001).

\section{La décolonisation : essor du roman et des essais}

Au début des années 1950, parallèlement à l'essor du roman africain, dans le contexte de la répression de Madagascar (1947), de la conférence de Bandung (1955), de l'indépendance du Ghana (1957) et surtout de la guerre d'Algérie (19541962), des essais au ton de plus en plus polémique prennent position à Paris contre le système colonial. En 1950, Aimé Césaire livre son célèbre Discours sur le colonialisme, d'abord chez Réclame, une édition qui passe relativement inaperçue ${ }^{9}$, puis dans une version revue et augmentée chez Présence Africaine en 1955. En 1952, un jeune psychiatre antillais âgé de vingt-sept ans, Frantz Fanon, publie aux éditions du Seuil Peau noire, masques blancs, préfacé par Francis Jeanson. En 1953, les éditions Présence Africaine publient Les Étudiants noirs parlent, bientôt suivi par Les Masses africaines et l'actuelle condition humaine d'Adoulaye Ly, avant la Lettre à Maurice Thorez d'Aimé Césaire (1956). En 1955, Richard Wright publie en première mondiale en français Bandung, 1500000000 d'hommes chez Calmann-Lévy. En 1957, Albert Memmi publie de son côté le Portait du colonisé chez Gallimard. En 1958, Présence Africaine sort la brochure de la Fédération des étudiants noirs de France (FEANF), Le Sang de Bandoeng (Traore 1985 : 3038; Diané 1990), composée notamment par Jacques Vergès, qui dénonce d'une manière virulente le recours à la torture en Algérie, la même année que $L a$ Question d'Henri Alleg chez Minuit. Publié à dix mille exemplaires, l'ouvrage est immédiatement saisi à l'imprimerie, et des perquisitions ont lieu dans les locaux et chez les responsables de la FEANF. Présence Africaine, déjà frappée par la censure du film d'Alain Resnais et Chris Marker que la maison d'édition avait coproduit en 1953, Les statues meurent aussi ${ }^{10}$, adopte une ligne plus prudente. Au début de l'année 1962, sa librairie, à l'instar de celle de François Maspero ou de celle des anarchistes du Monde libertaire, est plastiquée lors des "nuits bleues " de l'Organisation de l'armée secrète des partisans de l'Algérie française.

La guerre d'Algérie, qui plonge la IV République dans une crise qui lui est fatale, a un écho considérable dans le monde entier. Quelques maisons à l'avantgarde du champ éditorial, comme les éditions de Minuit de Jérôme Lindon, luttent contre la censure qui, après avoir réduit la presse au silence, frappe de plus

9. Une première version du texte avait paru dans la revue Chemins du monde en 1948, à l'occasion d'un texte de circonstance sur I'Union française. La traduction en anglais assura ensuite à l'œuvre un très grand retentissement. Voir Leiner $1993: 81$.

10. Malgré les protestations de ses auteurs, le film restera interdit jusqu'en 1963 et sera projeté dans une version abrégée. en plus durement les ouvrages. En 1959 sont créées à Paris les éditions Maspero, autour d'une librairie du quartier Latin, La Joie de lire (Hage 2009). De par sa formation et sa conviction politique, François Maspero est très sensible au problème colonial - il a suivi des cours d'ethnologie et fréquenté assidûment le musée de l'Homme et son ciné-club. Dès l'époque de sa première librairie, L'Escalier, qu'il a lancée en 1955, au coin de la rue Monsieur-le-Prince et de la rue Casimir-Delavigne, au cœur du quartier Latin à Paris, François Maspero a noué des liens étroits avec les intellectuels et écrivains du tiers-monde, ainsi qu'avec la nouvelle génération d'étudiants alors dits " coloniaux", tels l'angolais Mario de Andrade, le leader de 
la Guinée portugaise Amilcar Cabral, le cubain Nicolas Guillén, Léopold Sédar Senghor, Léon-Gontran Damas ou Richard Wright, à côté d'intellectuels communistes comme Claude Roy et Roger Vaillant. Il organise d'ailleurs en 1956 une signature du Discours sur le colonialisme d'Aimé Césaire, la semaine même où celui-ci démissionne du Parti communiste en publiant sa Lettre à Maurice Tho$r e z$, et s'intéresse de près cette même année au Premier Congrès des écrivains et artistes noirs à Paris, organisé par la Communauté africaine de culture d'Alioune Diop et qualifié de «Bandung culturel». Il diffuse les publications de Présence Africaine à côté du rapport Khrouchtchev qui fait suite au XXVI Congrès du Parti communiste d'Union soviétique. À côté de la librairie Présence Africaine, rue des Écoles à Paris, au catalogue très riche en français puis en anglais en 1962, la librairie de François Maspero devient le nouveau lieu de rendez-vous des intellectuels, des exilés et des militants africains. Jusqu'à Thomas Sankara, combattant révolutionnaire devenu président du Burkina-Faso, interrogé par la revue Jeune Afrique en 1986, qui se souvient avoir acheté ses livres chez Maspero :

- Jeune Afrique: Vous avez dans votre bureau, à Ouaga, les œuvres complètes de Lénine dans une très belle collection.

- Sankara : Oui, mais j'ai lu Lénine dans une collection plus pratique, un peu comme ces collections de poche que je trouvais à Paris quand j'allais m'approvisionner en livres au 1, place Paul-Painlevé, aux Herbes sauvages (Sankara 2007 : 280).

La mémoire du révolutionnaire de l'ancienne Haute-Volta coloniale connaît certes quelques approximations: Les Herbes sauvages, située dans le quartier de Belleville, était la librairie parisienne des maoïstes du Parti communiste marxiste-léniniste de France (PCMLF), tandis que le local de la place Paul-Painlevé, à quelques encablures de la rue Saint-Séverin, était le comptoir de vente des éditions Maspero après la vente de La Joie de lire en 1974.

François Maspero, alors très engagé dans les réseaux des porteurs de valises - ces Français qui luttent aux côtés du Front de libération national algérien -, publie bientôt L'An $V$ de la révolution algérienne, de Frantz Fanon, jusqu'alors auteur des éditions du Seuil, lesquelles adoptent une ligne plus modérée à partir de $1958^{11}$. Suit en novembre 1960 Au pied du mont Kenya, de Jomo Kenyatta, préfacé par Georges Balandier, qui est la thèse d'ethnologie, publiée en 1937 en anglais, d'un homme alors emprisonné par les Anglais, qui le considèrent comme le chef de la rébellion gikuyu. En 1961 sont publiés Les Damnés de la terre de Fanon, avec la préface retentissante de Jean-Paul Sartre, vers lequel François Maspero s'est tourné après les refus d'Aimé Césaire et d'Albert Memmi. Tenant particulièrement à ce livre, il écrit à Frantz Fanon le 24 septembre 1960, à propos de L'An $V$ : «Votre livre a représenté pour moi tout ce que devrait être ma collection : révolutionnaire et violente ${ }^{12}$. "Malgré les saisies, Les Damnés de la terre, immédiatement interdit comme son prédécesseur, est publié à plus de vint mille exemplaires pendant la guerre d'Algérie, avant de connaître un succès exceptionnel et d'être traduit dans des dizaines de langues de par le monde. Présence Africaine, qui ne s'était pas engagée dans la publication et dans la distribution de L'An $V$ après sa saisie, assure la traduction en anglais des Damnés de la terre ainsi que sa diffusion en Afrique. Bientôt, les livres publiés chez François Maspero interrogent le destin des pays qui ont accédé à l'indépendance. C'est le cas par exemple du livre de Seydou Badian publié en 1964, Les Dirigeants africains face à leur peuple. L'apparition des éditions Maspero ne tarde pas à «faire
-

11. Plusieurs écrivains du Seuil rejoignent alors Maspero : Frantz Fanon, Georges Suffert ou encore Francis Jeanson, même si les rivalités et les tensions entre Francis Jeanson et Henri Curiel au sein des réseaux de porteurs de valises ont pour conséquence que son livre, La Révolution algérienne, problèmes et perspectives, sort finalement chez l'éditeur milanais Feltrinelli en 1962.

12. Archives Fanon.

Correspondance avec François Maspero, Institut Mémoires de l'édition contemporaine, Caen. 
Fig. 7 Le Sang de Bandoëng de la Fédération des Étudiants d'Afrique noire en France, Paris, Présence Africaine, 1958; Au Pied du mont Kenya de Jomo Kenyatta, Paris, Maspero, 1960, ici dans la réédition de la Petite collection Maspero, 1967: édition française de la revue Tricontinental, publiée par François Maspero à Paris, $n^{\circ} 2$ de l'année 1970; Les Damnés de la terre de Frantz Fanon, Paris, Maspero, 1961.
- $\bullet$

13. En dépit de similitudes de vues et d'une solidarité de fait, les échanges et les collaborations sont des plus limités entre les deux maisons. On note par exemple une seule contribution de François Maspero à la revue, un hommage à Frantz Fanon rédigé après sa mort en 1962.

14. Archives du contrôle de la presse et du livre, année 1963, Centre des archives contemporaines, Fontainebleau.

15. Ibid. concurrence » à Présence Africaine, comme le note Amaly Aly Dieng $(1999: 49)^{13}$. Même si François Maspero s'engage très fortement aux côtés des révolutionnaires d'Amérique latine et conserve des liens privilégiés avec le Maghreb à l'issue de la guerre d'Algérie, il n'en délaisse pas pour autant l'Afrique noire, avec des ouvrages tels que Fidel Castro ou Tschombé en 1962, écrit par Maurice Rué sous l'impulsion de Jacques Vergès, ou les œuvres d'Amilcar Cabral et de Mario de Andrade. Il s'efforce aussi de publier les œuvres complètes de Frantz Fanon, tâche difficile car Josie Fanon a égaré les manuscrits de son époux. Redha Malek, l'ancien rédacteur en chef d'El Moudjahid, l'organe du FLN dans lequel écrivait Frantz Fanon, est ainsi consulté, alors qu'il est ambassadeur d'Algérie en Yougoslavie, pour attester la paternité des écrits de Fanon dans un journal où les articles étaient signés collectivement : le recueil Pour la Révolution africaine est ainsi publié en 1964. Lorsque Josie Fanon, considérant en 1967 que la position de Sartre à l'égard d'Israël est prosioniste, oblige François Maspero à enlever la préface, Les Damnés de la terre paraissent avec une préface amovible, sous la forme d'un feuillet à part inséré dans le livre. Bientôt, la maison d'édition publie d'autres figures de la pensée noire : de Malcom X en 1968 jusqu'aux Mémoires de Frederick Douglass en 1980 dans "Actes et Mémoires du peuple ", la dernière grande collection dirigée par François Maspero sous le pseudonyme de Louis Constant, avant son départ des éditions.

De nouvelles revues politiques françaises (Hage 2008) vont faire une large place à la situation politique en Afrique, dans le contexte de la décolonisation puis des indépendances : la revue Partisans de François Maspero, lancée en 1961, suivie un peu plus tard de sa rivale plus éphémère Révolution Afrique Asie Amérique (AAA), créée par Jacques Vergès après son départ forcé de Révolution africaine à Alger, et qui disposait d'une édition anglaise largement diffusée en Afrique, comme son homologue en langue française. Après 1968, la revue Tricontinental, émanation française sous la direction de François Maspero de la revue tiersmondiste de l'Organisation de solidarité des peuples d'Asie d'Afrique et d'Amérique (Ospaal), fondée à La Havane, accueille nombre d'auteurs africains, d'Amilcar Cabral à Sally N'Dongo, avant d'être étouffée par la censure. Après la guerre d'Algérie, les pouvoirs publics craignent de voir s'étendre la décolonisation aux départements français. Certains auteurs, comme Léonard Sainville, sont étroitement surveillés : la publication de son livre $\mathrm{Au}$ fond du bourg aux éditions de la Cité de Nils Andersson à Lausanne, une maison très engagée contre la guerre d'Algérie, est suivie par les affaires douanières ${ }^{14}$. Frantz Fanon reste quant à lui interdit aux Antilles par arrêté préfectoral, à l'initiative du ministre d'État chargé des départements et des territoires d'Outre-mer, Louis Jacquinot, qui avait déjà réclamé en 1964 auprès du ministre de l'Intérieur, Roger Frey, l'interdiction de la publication en France de Pour la révolution africaine ${ }^{15}$.

Les années 1950 et 1960 sont par ailleurs celles de l'essor du roman africain d'expression française des pays décolonisés, grâce à l'engagement des plus grandes maisons d'édition, Flammarion, Plon, Julliard ou Robert Laffont. Outre les titres déjà cités, de nombreux romans paraissent à la suite de L'Enfant noir (Plon, 1953) du guinéen Camara Laye : Le Pauvre Christ de Bomba de Mongo Beti chez Robert Laffont, sous le pseudonyme d'Alexandre Biyidi (1956), Le Docker noir de Sembène Ousmane, également en 1956, Une vie de boy du camerounais Fernand Oyono chez Julliard (1958), Kocumbo, l'étudiant noir d'Ake Loba chez Flammarion (1960). Présence Africaine n'est pas en reste, avec Soundjata ou l'épopée mandingue de Dibril Tamsir Niane (1960) ou Sous l'orage de Seydou Badian (1963). C'est 
FÉDÉRATION DES ÉTUDIANTS

D'AFRIQUE NOIRE EN FRANCE

(F E A N F)

\section{LE SANG} BANDOËNG

PRESENCE AFRICAINE

${ }_{17}$ bis, Rue de Chaligny PARIS (XII-)

\section{Jomo Kenyatta}

\section{Au pied du mont Kenya}

Préface de Georges Balandier. La première étude ethnologique africaine par un Africain, "le javelot flamboyant du Kenya”, devenue un manuel classique. Origine et système de parenté a Le système foncier $\mathrm{La}_{\mathrm{a}}$ vie économique « L'industrie cbez les Gikuyu m Le système educatif ${ }^{*} L$ 'initiation des garçons et des filles $\%$ La vie sexuelle des jeunes gens : Le système de gouvernement w La religion Gikuyu, le culte des ancitres et les sacrifices 蛅 La nouvelle religion $\%$ Medecine et magie.

FM / petite collection maspero
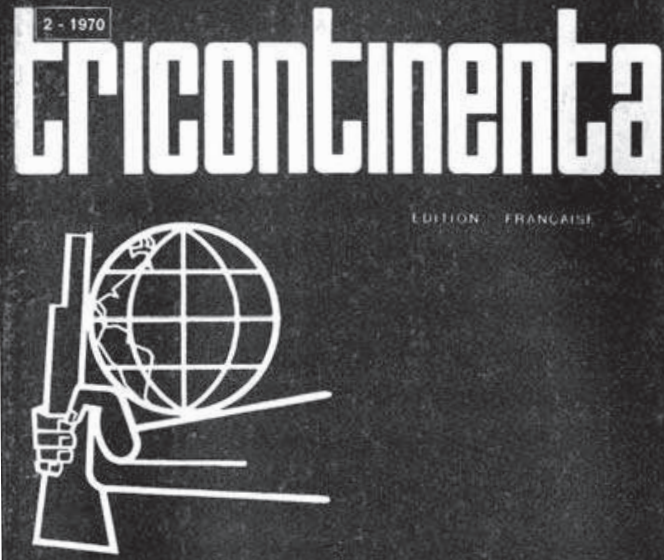

OSENDE AFANA

MARTYR DE LA REVOLUT ION AFR I CAINE

*

LES MÉTROPOLES CAPITALISTES ET LEURS CÓLONIES ' INTERIEURES',

( J . - P. SARTRE et J. - P. N'DIAYE)

$$
\text { * }
$$

LES TUPAMAROS EN ACTION 


\section{LES CONDITIONS NOIRES : UNE GÉNÉALOGIE DES DISCOURS}

alors l'âge d'or du roman africain, qui rencontre un succès critique avec de nombreux prix, tandis que sont créées des récompenses spécifiques pour les ouvrages d'auteurs africains, comme le grand prix de la littérature d'Afrique noire en 1961 (Cornevin 1976 : 187-188). L'Enfant noir reçoit ainsi le prix Charles Veillon, Ville cruelle de Mongo Beti le prix Sainte-Beuve en 1958, et Birago Diop le grand prix littéraire d'Afrique noire en 1964. Jean-Claude Blachère a pu nuancer cet engouement pour les littératures noires en montrant, témoignages de jurés à l'appui, qu'une telle reconnaissance consacrait surtout des formes romanesques académiques (Blachère 1993 : 54-55).

Une telle production, dans le contexte de la décolonisation, est évidemment fortement chargée d'une critique de l'emprise coloniale. Comme le rapporte Claude Wauthier dans L'Afrique des Africains : " "Enfin un roman africain qui n'a pas d'arrière-pensée politique." Tel était le cri du cœur d'un éditeur français présentant Mission terminée du camerounais Mongo Beti. La réflexion est peut-être d'autant plus justifiée que les deux premiers récits de l'auteur, Ville cruelle, signé du pseudonyme d'Ezo Boto, et Le Pauvre Christ de Bomba, étaient particulièrement sévères pour les colonisateurs » (Wauthier 1977 : 136). Présence Africaine joue ici encore un rôle important, procédant à un grand nombre de rééditions, souvent dans les éditions définitives qui feront date, des textes publiés chez d'autres éditeurs (du Discours sur le colonialisme de Césaire au Pauvre Christ de Bomba de Beti, que Laffont ne voudra plus commercialiser), des rééditions qui constituent la plus grande bibliothèque africaine contemporaine de l'édition française. Cet essor romanesque s'accompagne de celui des recueils de contes oraux traditionnels, notamment ceux de Birago Diop, Les Contes d'Ahmadou Koumba, déjà cité (Fasquelle, 1947, puis Présence Africaine, 1958), Les Nouveaux Contes d'Ahmadou Koumba (Présence Africaine, 1958) et Contes et savanes (Présence Africaine, 1963), ceux de Bernard Dadié, Légendes africaines (Seghers, 1954) et Le Pagne noir (Présence Africaine, 1955), ceux de Benjamin Matip, À la belle étoile, contes et nouvelles d'Afrique (Présence Africaine, 1962), Tchicaya Utam'Si, Légendes africaines (Seghers, 1967), ou encore Joseph Brahim, Seid Ayu Tchad sous les étoiles (Présence Africaine, 1962). À la fin des années 1960, une nouvelle génération de romanciers entend révolutionner l'écriture romanesque, un peu à la manière des écrivains africains anglophones, une démarche originale et inédite qui n'est pas immédiatement reconnue par le monde éditorial français, comme le souligne John Conteh-Morgan : «Si l'écrivain francophone se permet en français ce que fait un Achebe [...], comme c'est le cas d'Ahmadou Kourouma dans Les Soleils des indépendances (1968) ou de Nazi Boni des Crépuscules des temps anciens (1962), soit il n'est pas publié en France (ce qui est arrivé à Kourouma), soit il est accusé d'avilir la langue française. Et pourtant, s'il écrit dans un français pur, son œuvre est entachée de cette inauthenticité qui a amené Pierre-Henri Simon à dire des paysans de Cheikh Hamidou Kane, dans L'Aventure ambiguë, qu'ils s'exprimaient comme des existentialistes " (Conteh-Morgan 1989 : 34, cité in Blachère 1993 : 64). D’abord publié au Québec aux Presses universitaires de Montréal, le roman de Kourouma est bientôt acquis par le Seuil en 1970, dont il constitue aujourd'hui l'un des honorables succès (plus de cent mille exemplaires). Pour autant, un livre comme Le Devoir de violence de Yambo Oulouguem, publié au Seuil, reçoit en 1968 le prix Renaudot. Par ailleurs, Présence Africaine, les coéditions ORTF/ DAEC, avec leur collection «Répertoire théâtral africain », ainsi que les éditions Pierre-Jean Oswald et leur collection «Théâtre africain ", soutiennent l'essor du théâtre sur le continent (Ricard 1986). 
Avec les indépendances et l'essor des universités africaines, on assiste à partir des années 1960 à une diffusion élargie des textes, malgré les limites de l'alphabétisation et de l'accès matériel au livre, comme en témoigne l'écrivain sénégalais Boubacar Boris Diop : «Dans les années 70, cela faisait très chic de se promener sur le campus de l'université de Dakar avec certains livres. C'était la grande époque des éditions Maspero et la faveur des étudiants allait bien évidemment aux textes de Cheikh Anta Diop ${ }^{16}$, de Mao-Tsé-toung, d'Amilcar Cabral et d'autres auteurs dont il n'était jamais question dans les amphis» (Diop 2003: 87). Cette diffusion est facilitée par l'avènement des collections de poche : la "Petite Collection Maspero " (PCM) lancée en 1967, la collection de Présence Africaine créée en 1971, mais aussi "10/18 ", relancée par Christian Bourgois en 1968, qui va investir dans la littérature africaine. Autant de livres qui passent bientôt la Méditerranée et sont distribués en Afrique. Par ailleurs, de nouvelles maisons d'édition sont créées sur le continent africain avec l'aide des États. En 1963, les éditions du Centre de littérature évangélique de Yaoundé (CLE), d'abord orientées vers une production religieuse, se tournent bientôt vers le théâtre, la littérature, la poésie, la littérature enfantine ou les essais. En 1967, le Mali lance les Éditions populaires du Mali, devenues par la suite les Éditions et imprimeries du Mali, avec un catalogue de littérature orale et d'ouvrages de sciences humaines et sociales. En 1972, grâce à l'impulsion de Léopold Sédar Senghor, devenu président du Sénégal, sont créées les Nouvelles Éditions africaines (NEA), en collaboration avec des éditeurs français, Présence Africaine, Hachette, Nathan, Armand Colin et les éditions du Seuil, qui détiennent des parts dans l'entreprise. Les NEA, qui essaimeront par la suite à Abidjan et à Lomé, se consacrent avant tout à la production de manuels scolaires, mais également à celle d'œuvres de fiction et d'essais. Au Zaïre, on trouve les éditions Belles Lettres, celles du Centre africain de littérature, puis Okapi ou les éditions du Mont-Noir, et de nombreuses autres petites maisons d'édition à l'existence parfois éphémère. La plupart des pays disposent ainsi de leur propre système éditorial, qui, malgré des difficultés endémiques de distribution et de financement, prélude à l'apparition de littératures se concevant et se revendiquant désormais comme «nationales ».

$\mathrm{Au}$ tournant des années 1970, des critiques de plus en plus nombreuses et virulentes s'élèvent contre les régimes issus de la décolonisation et leur collusion avec un néocolonialisme persistant. Elles se retrouvent parmi les nombreuses collections de textes politiques qui font florès dans l'édition française de l'époque ("Combat» de Claude Durand ou "L'Histoire immédiate» de Lacouture au Seuil; "Témoins» chez Gallimard, "Contestation» chez Robert Laffont, etc.), un essor auquel Présence Africaine, avec ses collections «Textes politiques» ou "Leaders politiques du tiers-monde ", ne reste pas étrangère, mais que ses relations avec les chefs d'État africains issus des indépendances vont venir compliquer. Significativement, un nouveau paratexte vient parfois compléter les rééditions des ouvrages des écrivains, intellectuels ou militants d'avant l'indépendance qui ont ensuite accédé aux plus hautes responsabilités. Georges Balandier ajoute ainsi à sa préface à l'ouvrage Au pied du mont Kenya, lors de la réédition qui ouvre symboliquement la «Petite Collection Maspero » lancée en 1967, un second texte qui informe le lecteur que Jomo Kenyatta est désormais président du Kenya, et que son action à ce poste suscite bien des interrogations : « Jomo Kenyatta est au pouvoir, et le pouvoir l'a imprégné d'ambiguïté » (Balandier 1967 : 18). Certains écrivains rompent alors un long silence d'écriture par des livres très polémiques, tel Mongo Beti contre le régime d'Ahidjo au Cameroun. Tous ses éditeurs précédents ayant refusé le livre, l'écrivain se tourne vers François Maspero, qui le publie immédiatement. chez Présence Africaine en 1954, avec Nations nègres et cultures. 


\section{LES CONDITIONS NOIRES : UNE GÉNÉALOGIE DES DISCOURS}

Fig. 8 Mongo Beti

(c) Présence Africaine.

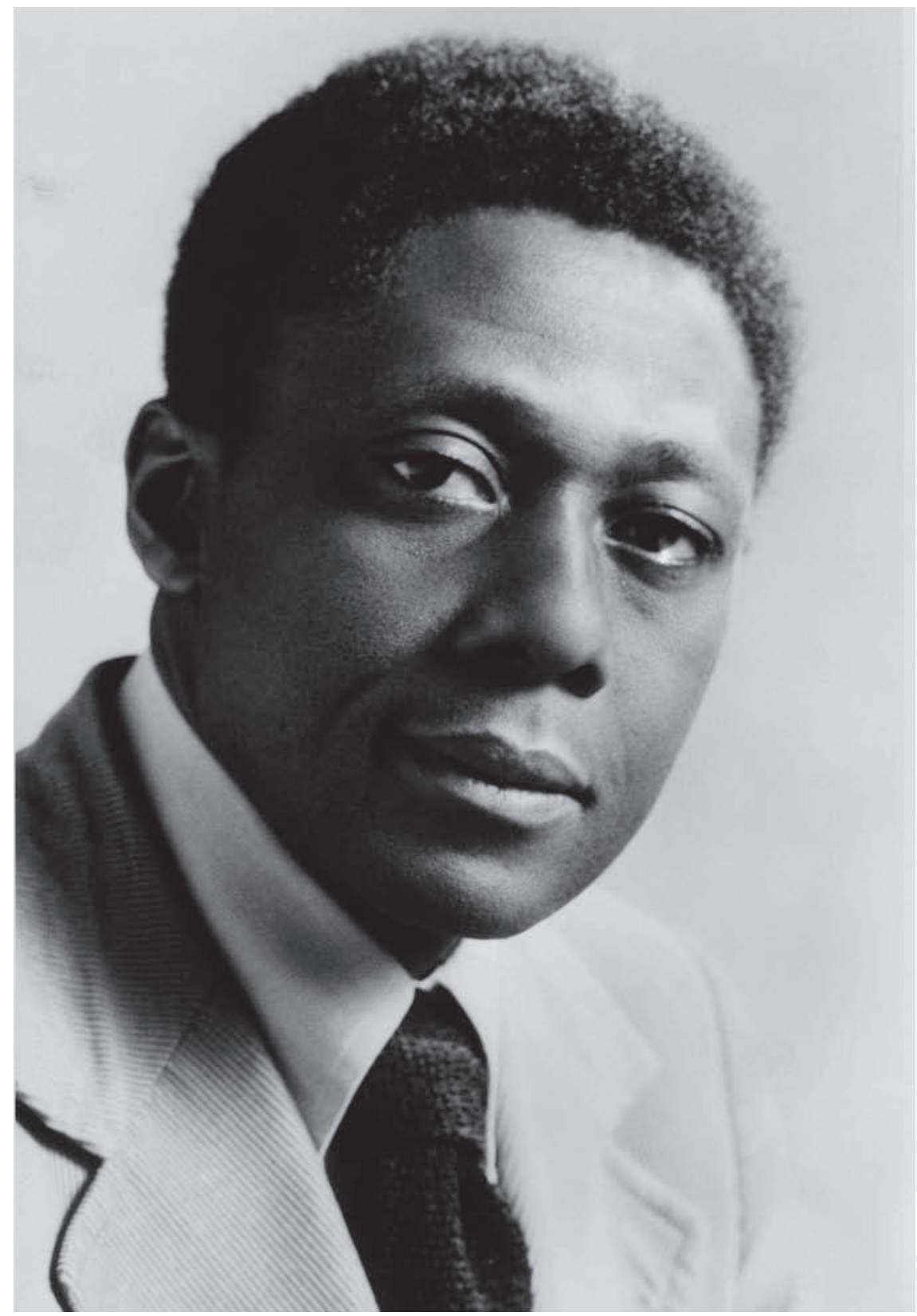

Les ouvrages consacrés à la situation politique en Afrique, à ce que FrançoisXavier Verschave appellera plus tard la «Françafrique », sont particulièrement visés par la censure chez Maspero, lui-même dans la ligne de mire du ministre de l'Intérieur Raymond Marcellin : La Grande mystification du Congo Kinshasa, les crimes de Mobutu de Cléophas Kamitatu (1971), Main basse sur le Cameroun, autopsie d'une décolonisation de Mongo Beti (1972), et même L'Ascension de Mobutu : du général Sésé Seko au maréchal Mobutu (1974), qui n'est autre que la plaidoirie prononcée au procès de Kamitatu par Jules Chomé, avocat belge d'origine zaïroise, sont ainsi poursuivis et interdits, toute réédition ou diffusion étant sanctionnée par de lourdes amendes. L'article 14 de la loi sur la presse de 1881, modifié par un décret de septembre 1939 sur les "publications de provenance étrangère ", ainsi 
que l'article relevant des «injures à chef d'État étranger », sont les armes privilégiées par les pouvoirs publics. Mongo Beti est sans doute l'exemple le plus absurde de l'arbitraire des condamnations : son ouvrage est en effet proscrit en vertu de la "provenance étrangère " de son auteur, alors que ce dernier est professeur de lettres certifié, devenu ensuite agrégé en France, à une époque où les statuts de la fonction publique exigent la nationalité française. L'affaire permet en tout cas de mettre en place un double système de stigmatisation de l'auteur - «étranger » en France, mais «français " au Cameroun - dans le but d'ôter toute crédibilité à ses critiques. Il faut attendre 1976 pour qu'un tribunal de Rouen revienne en appel sur le bien-fondé de l'interdiction. Entre-temps, les livres ont été réédités à l'étranger, au Québec pour Mongo Beti, en Belgique chez Complexe pour Kamitatu, et importés clandestinement en France : la mention "Livre saisi en France " portée sur la quatrième de couverture compliquera d'ailleurs la tâche de Beti lorsqu'il se rendra à la douane du port de Rouen pour réceptionner les livres (Beti 2006 : 97-98). De 1971 à 1973, Maspero publie pour sa part la revue Acoma, «revue de littérature, de sciences humaines et politiques » d'Édouard Glissant et de l'Institut d'études martiniquaises, créé en 1965 (Fonkoua 1998; Acoma 2005), et qui témoigne de son engagement en faveur des Antilles. Patrick Chamoiseau voit aujourd'hui en François Maspero le "colibri ", l'oiseau symbole de la liberté aux Antilles : "Maspero, pour moi, c'est d'abord une légende. Comme un mantra d'initiés, un vocable qui accompagnait l'interdit, le subversif, le marronnage, la résistance qui se prépare au bond. C'est aussi comme un bout de formule secrète qui inaugurait la mise en transformation de moi-même et du monde. Les étudiants antillais revenaient de France, dans les années 60 (j'étais très jeune à l'époque) avec des livres estampillés Maspero qu'ils cachaient dans leurs valises. Je ne l'ai pas directement connu mais il paraît que les Renseignements Généraux veillaient à l'époque, que leurs valises étaient fouillées, et que se trouver en détention d'un livre Maspero faisait de vous une sorte d'ennemi public. Si bien qu'avant même le livre d'un quelconque auteur, avant même que cela soit Fanon ou le Che, ou des textes sur la guerre d'Algérie ou sur le stalinisme, c'était le vocable Maspero qui résonnait comme sésame infernal. Les livres colorés baignaient dans cette aura. Il y avait comme une palpitation à se saisir de l'un d'entre eux, et à l'emporter avec soi. Le simple fait d'en détenir c'était déjà charroyer un début d'explosif... » (Chamoiseau 2009 : 89-92).

Au milieu des années 1970 : reconnaissance et renouvellement

En 1975, une nouvelle génération d'éditeurs vient poursuivre en France l'œuvre de Présence Africaine ou de François Maspero, lesquels, après une longue phase de croissance, connaissent désormais, dans un contexte politique très différent, de graves difficultés économiques. Les éditions L'Harmattan sont créées à Paris et reprennent bientôt le fonds des éditions Pierre-Jean Oswald, puis les éditions Akpagnon lancées à Paris en 1978, avant que les maisons d'édition Karthala et Silex ne voient le jour au début des années 1980.

Le milieu des années 1970 est marqué par la reconnaissance définitive de ces littératures noires, tant dans le champ éditorial français qu'au plan international, et par le début d'une grande vague de travaux universitaires et d'essais qui leur sont consacrés. Ces littératures, portées par des auteurs reconnus, sont en effet arrivées à maturité, et il est loin, le temps où Mongo Beti pouvait ironiser 
-

17. Un écho à la formule employée par Albert Memmi dans son Portrait du colonisé, paru chez BuchetChastel en 1957: « La littérature colonisée de langue européenne me semble condamnée à mourir jeune. » en lançant sa célèbre boutade sur le statut des auteurs africains : "On est toujours un jeune écrivain africain ${ }^{17}$. » Dès 1973, Nadine Gordimer, dans son livre The Black Interpreters (Gordimer 1973), dresse un premier bilan, à l'échelle de l'Afrique tout entière et toutes langues confondues, des œuvres littéraires du continent: " pour elle Senghor était le plus grand poète, Soyinka le plus grand dramaturge, et Achebe le seul romancier de classe internationale» (Ricard $1995: 236$ ).

Le mouvement de la négritude commence toutefois à connaître un relatif épuisement et doit faire face à des critiques de plus en plus sévères, à la suite de celle du nigérian Soyinka, bien connue, selon laquelle « un tigre ne proclame pas sa tigritude. Il bondit sur sa proie et la dévore ». Le mouvement est relayé par les nouvelles thèses sur la créolité (Chamoiseau et Confiant 1991), portées par exemple par un Patrick Chamoiseau, dont le roman Texaco se voit couronné par le prix Goncourt en 1992. L'accès des anciennes colonies à l'indépendance a déplacé les enjeux vers la question, il est vrai très discutée dès les années 1950, des «littératures nationales », et vers celle de la littérature postcoloniale (Moura 1999).

Les œuvres de littérature africaine accèdent désormais au rang de classiques, même si «la notion n'est pas une évidence, qui plus est lorsqu'elle s'applique à la littérature africaine» (Mouralis 2005-2006). Elles font également progressivement leur entrée dans les programmes scolaires, en France et surtout en Afrique : si, en 1964, Abdou Moumouni pouvait déplorer le peu de place qui leur était octroyé dans l'enseignement (Moumouni 1964), elles sont désormais au cœur des programmes scolaires. Certains auteurs, longtemps relégués dans la catégorie marginale de "littérature populaire», comme Félix Couchouro, voient publiées leurs œuvres complètes. Après celle des Kourouma, Ouloguem ou Boni, une nouvelle génération d'auteurs prend le relais. Dans les années 1980 et 1990, l'essor de la littérature africaine ne se dément pas : en 1997, le numéro 129 de Notre librairie recense ainsi mille cinq cents titres pour les années 1988 à 1996.

La plupart des auteurs relèvent désormais de la catégorie «Littérature africaine", quand ils ne sont pas rangés dans celle plus générale de «littérature étrangère » chez les plus grands éditeurs, d'Actes Sud à Gallimard, en passant par les éditions du Seuil ou Le Serpent à plumes. Des collections leur sont spécifiquement consacrées, ainsi "Monde noir " chez Hatier, dirigée par Jacques Chevrier, d'abord en poche puis en édition classique, ou "Continents noirs", créée chez Gallimard en 2000, qui comprend également des auteurs traduits, notamment Donato N'Dongo, né en Guinée équatoriale, traduit de l'espagnol, ou l'angolais José Eduardo Agalosa, traduit du portugais. Cette dernière collection dépasse aujourd'hui les cent mille exemplaires de tirage global, même si les meilleures ventes culminent souvent à deux mille exemplaires.

Université de Bourgogne / CHCSC (UVSO) hagejulien@hotmail.com

mots clés / keywords : édition francophone // francophone publishing • littératures d'Afrique noire // Black African literature • littérature coloniale // colonial literature $•$ négritude // negritude $\bullet$ censure // censorship $•$ décolonisation // decolonization • néocolonialisme // neocolonialism. 


\section{Bibliographie}

\section{Albertini, Jean}

1981 Avez-vous lu Jean-Richard Bloch ? Paris, Éditions sociales.

Antoine, Régis

1992 La littérature franco-antillaise. Paris, Karthala.

\section{Astier-Loufti, Martine}

1971 Littérature et colonialisme. L'expansion coloniale vue dans la littérature romanesque française, 1871-1914. Paris et La Haye, Mouton.

\section{Balandier, Georges}

1967 [Préface, additif à la nouvelle édition], in Jomo Kenyatta, Au pied du mont Kenya. Paris, Petite Collection Maspero $1:$ 17-18.

\section{Bancel, Nicolas et Devisse, Jacques}

1993 « La presse étudiante noire de 1943 à 1960 », in Le Rôle des mouvements d'étudiants africains dans l'évolution politique et sociale de I'Afrique depuis les années 1960. Paris, Unesco et L'Harmattan : 197-223.

\section{Benot, Yves}

1989 Les Parlementaires africains à Paris, 1914-1915. Paris et Dakar, Chaka.

\section{Beti, Mongo}

2006 Mongo Beti parle, Entretiens avec Ambroise Kom, Testament d'un esprit rebelle. Paris, Homnisphères.

\section{BLACHÈRE, Jean-Claude}

1981 Le Modèle nègre. Aspects littéraires du mythe primitiviste au xx siècle chez Apollinaire, Cendrars, Tzara. Dakar, Abidjan et Lomé, Nouvelles Éditions africaines.

1993 Négritures, les écrivains d'Afrique noire et la langue française. Paris, L'Harmattan.

2003 « Fortunes de la littérature coloniale dans l'avant-garde française », in « Littératures et colonies », Cahiers du SIELEC 1 : 285-305.

Buata, Malela B.

2008 Les Écrivains afro-antillais à Paris, Stratégies et posture identitaire. Paris, Karthala.

\section{Casanova, Pascale}

1999 La République mondiale des lettres. Paris, Seuil.

\section{Chamoiseau, Patrick}

2009 «Entretien avec Bruno Guichard », in Bruno Guichard, Julien Hage, Alain Leger, François Maspero et les paysages humains.
Lyon, À plus d'un titre et La Fosse-aux-Ours, 2009 : 89-92.

\section{Chamoiseau, Patrick et Confiant, Raphaël}

1991 Lettres créoles, tracées antillaises et continentales, 1635-1975. Paris, Hatier.

\section{Chevrier, Jacques}

1996 Littératures francophones d'Afrique noire. Aix-en-Provence, Édisud.

\section{CONTEZ-MORGan, John}

1989 «A la découverte de l'autre.

Traduire d'anglais en français », Notre librairie, Revue des littératures du Sud 98, juillet-septembre : 21-3?.

\section{Cornevin, Robert}

1976 Littératures d'Afrique noire d'expression française. Paris, PUF.

\section{Corzani, Jack, Hoffmann, Léon-}

François et Picione, Marie-Lyne 1998 Littératures francophones. II : Les Amériques. Haïti, Antilles-Guyane. Québec et Paris, Belin Sup.

\section{Couchouro, Félix}

1941 Amour de féticheuse. Ouidah, Imprimerie P. D'Almeida.

\section{DAMAs, Léon-Gontran}

1939 «La Parole aux réprouvés », Esprit, juin : 333-354.

1947 Latitudes françaises. I: Poètes d'expression française, Afrique noire, Madagascar, Réunion, Guadeloupe, Martinique, Indochine, Guyane, 1900-1945. Paris, Seuil.

Delavignette, Robert

1948 [Préface], in Ousmane Socé, Karim. Paris, Nouvelles Éditions latines : 7-15.

Dewitte, Philippe

1985 Les Mouvements nègres en France, 1919-1939. Paris, L'Harmattan.

1989 «Le Paris noir de l'entre deux-guerres », in André Kaspi et Antoine Marès (dir.], Le Paris des étrangers depuis un siècle. Paris, Imprimerie nationale : $157-170$.

1994 «Intellectuels et étudiants africains à Paris à la veille des indépendances », in Antoine Marès et Pierre Milza (dir.), Le Paris des étrangers depuis 1945. Paris, Publications de la Sorbonne : 319-342. 1998 « Les Africains en France de 1914 à 1960 : naissance d'une élite moderne », in Laurent
Gervereau, Pierre Milza et Émile Témime [dir.], Toute la France : Histoire de l'immigration en France au xx siècle. Paris, Somogy : 164-174.

DianÉ, Charles

1990 La Fédération des étudiants d'Afrique noire en France (FEANF) et les grandes heures du mouvement syndical étudiant noir. Paris, Chaka.

Dieng, Amaly Aly

1999 « Regards sur l'itinéraire de Présence Africaine », 1947-1997, Cinquantième anniversaire de la revue Présence Africaine, Dakar, 25-27 novembre 1997. Paris, Présence Africaine, numéro spécial : 43-51.

Diop, Birago

1978 La Plume raboutée. Paris, Présence Africaine et Nouvelles Éditions africaines.

\section{Diop, Boubacar Boris}

2003 «Mongo Beti et nous », in Ambroise Kom [dir.], «Remember Mongo Beti », Bayreuth African Studies 67 : 87-92.

ÉDITIONS DU SEUIL

2006 Littératures francophones au Seuil : 1945-2006 : une histoire. Paris, Seuil.

FABRE, Michel

1990 « De Batouala à Doguicimi », in Alain Ricard et Janos Riesz (dir.), Semper aliquid novi : littérature comparée et littératures d'Afrique. Mélanges offerts à Albert Gérard. Tübingen, G. Narr : 239-249.

\section{FANOUH-SieFER, Léon}

1980 Le Mythe du nègre et de l'Afrique noire dans la littérature française (de 1800 à la Seconde Guerre mondiale). Dakar, Nouvelles Éditions africaines.

\section{FonKOUA, Romuald}

1998 « Instituer le savoir des Antilles aux îles : l'Institut martiniquais d'études et la revue Acoma », in D. de Ruyter-Tognotti et M. Van Strien-Chardonneau (dir.), Le Roman francophone actuel en Algérie et aux Antilles. Groningue, CRIN : 103-120.

\section{Geneste, Elsa}

2009 « Lucie Cousturier, René Maran, JeanRichard Bloch : Réflexions sur le sens de l'engagement en faveur des Noirs au lendemain de la Grande Guerre », in Roger Little (dir.), Lucie Cousturier, les Tirailleurs et la question coloniale. Paris, L'Harmattan : 187-20?. 
GÉRARD, Albert

1992 Littératures en langues africaines.

Paris, Mentha.

Gide, André

194 ? « Avant propos », Présence Africaine 1: 3-6.

GoRDIMER, Nadine

1973 The Black Interpreters. Johannesburg, Ravan Press.

\section{GRÉGOIRE, Abbé}

1991 De la littérature des nègres ou Recherches sur leurs facultés intellectuelles, leurs qualités morales et leur littérature. Paris, Librairie académique Perrin.

HAge, Julien

2008 « Sur les chemins du Tiers-Monde en lutte : Partisans, Révolution, Tricontinental (1961-1973) », in Philippe Artières et Michelle Zancarini-Fournel (dir.], 68, une histoire collective (1962-1981). Paris, La Découverte : 86-93.

2009 « Une brève histoire des éditions Maspero », in Bruno Guichard, Julien Hage et Alain Leger, François Maspero et les paysages humains. Lyon, À plus d'un titre et La Fosse-aux-Ours : 93-160.

Halen, Pierre

1993 Le petit Belge avait vu grand, une littérature coloniale. Bruxelles, Labor.

HARDY, Georges

1938 [Préface], in Hazoumé 1938 : 9-11.

Hausser, Michel

1975 Les Deux Batouala de René Maran. Bordeaux et Sherbrooke, Sobodi et Naman. 1988 Pour une poétique de la négritude I. Paris, Silex.

\section{Hausser, Michel et Mathieu, Martine}

1998 Littératures francophones. III :

Afrique noire, océan Indien. Paris, Belin.

Hazoumé, Paul

1938 Doguicimi. Paris, Larose.

\section{HowletT, Jacques}

1976 Index alphabétique des auteurs et des matières, 1947-1976. Paris, Présence Africaine.

\section{Kane, Mohamadou}

1985 [Préface], in Bakary Diallo, Force-Bonté. Paris, Nouvelles Éditions africaines : III-XIX

Kesteloot, Liliyan

2001 Histoire de la littérature négro-africaine. Paris, Karthala.

\section{LeBeL, Roland}

1931 Histoire de la littérature coloniale en

France. Paris, Larose.

LEINER, Jacqueline

1993 Aimé Césaire, Le Terreau primordial. Tübingen, Günther Narr.

LORDEREAU, Paulette, avec la collaboration de Luadia L. NTAMBWE 1991 Littératures africaines à la Bibliothèque nationale. 1920-1972 : Catalogue des ouvrages d'écrivains africains et de la littérature critique s'y rapportant entrés à la Bibliothèque nationale. Paris, Bibliothèque nationale de France.

\section{LÜSEBRINK, Hans-Jürgen}

1990 Schrift, Buch und Lektüre in der französischsprachigen Literatur Afrikas : zur Wahrnehmung und Funktion von Schriftlichkeit und Buchlektüre in einem kulturellen Epochenumbruch der Neuzeit. Tübingen, Niemeyer.

1991 La Conquête de l'espace public colonial. Francfort, IKO.

MARAN, René

1921 Batouala, véritable roman nègre. Paris, Albin Michel.

\section{Mateso, Locha}

1986 La Littérature africaine et sa critique. Paris, Karthala.

\section{MolLier, Jean-Yves}

1995 «Paris capitale éditoriale des mondes étrangers », in Antoine Marès et Pierre Milza [dir.), Le Paris des étrangers depuis 1945. Paris, Presse de la Sorbonne : 373-394.

2001 «La construction du système éditorial parisien et son expansion dans le monde du xvIII au xx ${ }^{e}$ siècle », in Les Mutations du livre et de l'édition dans le monde du xVIII' siècle à l'an 2000. Sainte-Foy, Presses de l'Université Laval, et Paris, L'Harmattan : 66-?0.

Moumouni, Abdou

1964 L'Éducation en Afrique. Paris, Maspero.

MourA, Jean-Marc

1999 Littératures francophones et théorie postcoloniale, enjeux et débats. Paris, PUF.

\section{Mouralis, Bernard}

1984 Littérature et développement : essai sur le statut, la fonction et la représentation de la littérature négro-africaine d'expression française. Paris, Silex et ACTT.

2005-2006 «Qu'est-ce qu'un classique africain ? », Notre librairie, Revue des littératures du Sud 160, décembre-février : 34-40.
Mouralis, Bernard et Piriou, Anne (dir.), avec la collaboration de Romuald FonKOUA

2003 Robert Delavignette savant et politique [1897-1976]. Paris, Karthala.

OnANA, Charles

2007 René Maran, le premier Goncourt noir. Paris, Duboiris.

PORRA, Véronique

1994 L'Afrique dans les relations francoallemandes entre les deux guerres : enjeux identitaires des discours littéraires et de leur réception. Francfort, IKO.

\section{Proteau, Laurence}

2001 «Entre poétique et politique, Aimé Césaire et la négritude », Sociétés contemporaines 44 : 15-39.

Pujarniscle, Eugène

1931 Philoxène ou de la littérature coloniale. Paris, Firmin-Didot.

Queneau, Raymond (dir.)

1958 Encyclopédie de la Pléiade, vol. ? : Littératures françaises, connexes et marginales. Paris, Gallimard.

RICARD, Alain

1986 L'Invention du théâtre, le théâtre et les comédiens en Afrique noire. Lausanne, L'Âge d'homme.

1987 Naissance du roman africain : Félix Couchouro (1900-1968). Paris, Présence Africaine.

1995 Littératures d'Afrique noire, des langues aux livres. Paris, CNRS et Karthala.

\section{Riesz, Janos}

1989 (avec Joachim Schulz) «Tirailleurs sénégalais 》. Présentations littéraires et figuratives de soldats africains au service de la France. Francfort, Lang, 1989.

2007 a « Littératures africaines en langues européennes et littératures européennes. Rapports entre textes et champ littéraire », in De la littérature coloniale à la littérature africaine. Paris, Karthala : 15-42.

$2007 \mathrm{~b}$ « De l'ethnographie au roman africain », in De la littérature coloniale à la littérature africaine. Paris, Karthala : 250-268.

\section{Rubiales, Lourdes}

2005 « Notes sur la réception du Goncourt en France », Francofonia 14 : 123-145.

Ruscio, Alain

2008 « Littérature, chansons et colonies 
(1900-1920) », in Pascal Blanchard, Sandrine Lemaire et Nicolas Bancel (dir.), Culture coloniale en France, de la Révolution française à nos jours. Paris, CNRS et Autrement : 131-142.

\section{SANKARA, Thomas}

2007 «Sur les livres et la lecture : entrevue avec Jeune Afrique, février 1986 », in Thomas Sankara parle : la révolution au Burkina Faso, 1983-1987. Londres et Paris, Pathfinder Press.

\section{SAPIRO, Gisèle}

1999 La Guerre des écrivains : 1940-1953.

Paris, Fayard.

\section{SAVARÈSE, Eric}

1999 « Livres noirs pour petits blancs, constructions littéraires et usages idéologiques de l'altérité radicale », in Littératures et temps colonial. Aix-en-Provence, Édisud: 209-223.

\section{SERRY, Hervé}

2008 Les Éditions du Seuil, 70 ans d'histoire. Paris, Seuil.

\section{STÄDLER, Katharina}

2001 La Négritude en France : À propos d'un champ littéraire colonisé en exil, in Romuald Fonkoua et Pierre Halen, Les Champs littéraires africains. Paris, Karthala : 193-209.

\section{Steins, Martin}

1986 "Black Migrants in Paris", in Albert Gérard

(dir.), European-language Writing in Sub-saharian Africa I. Budapest, Akademiai Kiado : 354-378.

\section{Thiesse, Anne-Marie}

1991 Écrire la France. Le mouvement littéraire régionaliste de langue française entre la Belle Époque et la Libération. Paris, PUF.

\section{TRAORE, Sekou}

1985 La Fédération des étudiants d'Afrique noire en France (FEANF). Paris, L'Harmattan.

\section{VAN Hove, Juliette}

1987 «Les Revues du monde noir », La Revue des revues $3: 30-40$.

\author{
WaUthier, Claude \\ 1977 L'Afrique des Africains, inventaire de \\ la négritude. Paris, Seuil.
}

\section{Acoma}

2005 Acoma, revue de littérature, de sciences humaines et politiques, édition complète, $n^{\circ}{ }^{\circ} 1-5$, rééd. Perpignan, Presses universitaires de Perpignan.

\section{Cat. exp. Roanne \\ 1988 Guy Levis Mano, poète, typographe, éditeur (Roanne, galerie de la bibliothèque Déchelette, 2 mars-30 avril 1988). \\ Roanne, bibliothèque Déchelette. \\ Tropiques \\ 1994 Tropiques 1941-1945: \\ collection complète [reprod. en fac-simimilé], précédé de «Entretien avec Aimé Césaire 》 par Jacqueline Leiner et « Pour une lecture critique de "Tropiques" » par René Ménil. Paris, Jean-Michel Place.}

\section{Résumé / Abstract}

Julien Hage, Les littératures francophones d'Afrique noire à la conquête de l'édition française (1914-1974] - L'article entend suivre l'émergence des littératures noires francophones, du lendemain de la Première Guerre mondiale jusqu'au milieu des années 1970, à travers leur écho et leur croissante reconnaissance au sein de l'édition française. Portées par les avant-gardes et le mouvement de la négritude, ces littératures s'émancipent progressivement de la catégorie de «littérature coloniale » dans laquelle elles ont longtemps été cantonnées. Elles s'imposent au lendemain de la Seconde Guerre mondiale, l'essor du roman relayant les succès de la poésie, et leurs auteurs sont alors publiés dans les plus grandes collections. La décoIonisation et les indépendances des pays du Tiers-monde amènent bientôt une nouvelle génération d'auteurs, et des textes au contenu plus politique, qui eurent maille à partir avec la censure.
Julien Hage, The Conquest of French Publishing by Francophone Literature from Sub-Saharan Africa [1914-1974] - This article intends to follow the emergence of black francophone literature from the end of the First World War until the middle of the 1970s, through the lens of its resonance and growing recognition within French publishing. Carried forward by the avant-gardes and the negritude movement, this field of literature progressively emancipated itself from the category of "colonial literature" that it had been restricted to for a longtime. This literature imposed itself after the Second World War, with the novel taking the place and success that poetry had previously held. Black authors were soon being published in the biggest collections. Decolonization and the independence of third-world countries lead to a new generation of authors and texts, with an increasingly political stance, and who had a bone to pick with censorship. 